\section{HACIA UNA FENOMENOLOGÍA NEGATIVA DE LOS SUEÑOS}

\author{
Gabriel Schutz \\ Universidad Nacional Autónoma de México \\ gabriel.schutz@gmail.com
}

\section{TOWARDS A NEGATIVE PHENOMENOLOGY OF THE DREAMS}

\begin{abstract}
In the first part of the essay, I describe phenomenologically the transition between dreaming and wakefulness in order to determine whether a reliable dream memory can result from this transition (after all, we have no evidence of our dreams other than our memories). This description shows that this is indeed the case and indicates the conditions under which we can apprehend dreams without imposing on them meanings they do not have. These conditions, or "attitude" is theoretically supported by a negative phenomenology of dreams, namely, a phenomenology which describes dreams by stating what they are not. This first part also explains why we usually forget our dreams and accounts for the cases in which we are conscious of dreaming. In the second part I sketch out a negative phenomenology. This phenomenology shows that the attributions consisting in qualifying dreams, or assigning them hidden originary meanings in need of deciphering (or interpreting), or their own teleology, as well as certain positive attributions (i.e. those that start by affirming: "dreams are such and such") are nonsensical. The conclusions demonstrate the continuity between the "threshold or transitional phenomenology" developed in the first part, and the negative phenomenology developed in the second.
\end{abstract}

KEY WORDS: Dreams, wakefulness, threshold, limit, negative phenomenology, receptivity, activity of the Ego, passive consciousness, interpretation of dreams.

\section{ENTRE El SOÑAR Y LA VIGILIA: UNA FENOMENOLOGÍA DEL UMBRAL}

1. Necesidad de una investigación crítica acerca de la evidencia con que contamos para un estudio de los sueños

Antes de iniciar un estudio sobre los sueños, no debería pasarse por alto que el soñar y la vigilia son dos "estados de conciencia" que parecen excluirse el uno al otro (estar en vigilia implica no estar soñando y al revés) ${ }^{1}$ y que esto sitúa la reflexión teórica, y en particular, la investigación fenomenológica, en una situación problemática: queremos teorizar sobre algo (los sueños) cuyo mostrarse implica la cancelación de la vigilia, que es cuando podemos llevar adelante un estudio teórico.
RESUMEN: En la primera parte del ensayo, describo fenomenológicamente la transición entre el soñar y la vigilia, a fin de determinar si de este umbral puede resultar un recuerdo-de-sueño fiable (pues no tenemos otra evidencia sobre los sueños sino nuestros recuerdos). La descripción muestra que sí y señala a la vez las condiciones requeridas para aprehender los sueños de modo de no inocularles determinaciones que les son ajenas. La "actitud" así sugerida encuentra su expresión teórica en una fenomenología negativa de los sueños, es decir, una fenomenología que sólo los describe por aquello que no son. Esta primera parte permite, además, explicar el olvido de los sueños y los casos en los que se tiene conciencia de estar soñando. La segunda parte es un esbozo de fenomenología negativa; muestra que aquellas atribuciones que consisten en calificar a los sueños, o adjudicarles sentidos ocultos y originarios que requieren ser descifrados (o interpretados), o una teleología propia, son, al igual que ciertas atribuciones positivas (i.e. que parten por decir: "Los sueños son asi y asi"), sinsentidos. Las conclusiones dejan ver la continuidad entre la "fenomenología del umbral" de la primera parte, y la fenomenología negativa de los sueños, de la segunda.

PALABRAS CLAVE: Sueños, vigilia, umbral, límite, fenomenología negativa, receptividad, actividad del yo, conciencia pasiva, interpretación de los sueños.

Nuestra evidencia primera se insinúa inaccesible y lo único que nos queda es confiar en el testimonio de la memoria y tomar por evidencia, ya no lo sueños, sino los recuerdos de sueños.

Ahora bien, si, como parece, nuestra única evidencia fenomenológica son recuerdos de sueños, lo primero que se impone es estudiar la fiabilidad de esos recuerdos; esto es, si los recuerdos comunican de manera fiable el soñar y la vigilia o no. Si resulta que hay recuerdos-de-sueños fiables, será preciso estudiar si algunos lo son más que otros $y$, de ser así, cuáles son las condiciones que determinan la mayor o menor fiabilidad; por último, qué es lo que se pierde, si algo, al tener por única evidencia recuerdos de sueños, en lugar de sueños, suponiendo que este extravío pudiera ser reconocido. 
Hasta donde he podido ver, los distintos aportes para una fenomenología de los sueños se han lanzado a determinar qué es el soñar y qué son los sueños, dando por sentada la entera fiabilidad de nuestros recuerdos, y sin haber desarrollado antes una crítica -aquí, en un sentido muy próximo al kantiano- de nuestras posibilidades de acceso a un "fenómeno" tal'. Por otro lado, la falta de una descripción que permita ver cómo es que se da la comunicación entre el soñar y la vigilia, le abre de inmediato la puerta al escepticismo, no sólo al clásico problema cartesiano (cómo puedo saber si no estoy soñando, cuando no hay indicios ciertos para distinguir el soñar de la vigilia) ${ }^{3}$, sino a la posibilidad de cuestionar que los sueños sean experiencias. En este punto, ha sido la filosofía analítica la que más ha insistido4.

Parece, pues, que ensayar una descripción fenomenológica del umbral en el que el soñar y la vigilia se tocan, puede prestar algún servicio, ya sea para afirmar el trabajo efectivamente realizado en materia de fenomenología de los sueños, o para indicar posibles rectificaciones, o bien para favorecer los cuestionamientos provenientes desde la filosofía analítica.

\section{2. ¿Cómo puede la conciencia de vigilia recordar algo que nunca se le ha presentado? (¿Problema falso o verdadero?)}

Veamos la expresión: recuerdo de un sueño (o sueño recordado). Se trata de una especie peculiar de recuerdo. Por esencia, un recuerdo re-presenta, o vuelve a hacer presente, sentidos de vivencias vividas en el pasado. Pero, en general, los sentidos que vuelven a comparecer pertenecen a impresiones que fueron originariamente percibidas en vigilia. Recordamos en vigilia el sentido de una vivencia pasada, vivida, en su momento, también en vigilia ${ }^{5}$.

Éste parece no ser el caso con el recuerdo de un sueño; aquí, el recordar, la nóesis rememorativa, sucede en vigilia, mientras que lo recordado re-presenta sentidos que no fueron originariamente percibidos en vigilia. De otro modo: en vigilia se recuerda, se re-presenta, aquello que originariamente se ha presentado en no-vigilia, aquello que nunca ha sido percibido por el yo de vigilia. ¿Cómo PUEDE EL YO DE VIGILIA RECORDAR AQUELLO QUE NUNCA PERCIBIÓ? ¿Tendría sentido hablar, entonces, de recordar sueños, cuando, al parecer, esto contradiría la esencia misma del recordar, es decir, cuando se trataría de la re-presentación de algo nunca antes presentado al yo que ahora recuerda? ¿0 es que la pregunta entraña una separación falsamente radical, un abismo insalvable entre el soñar y la vigilia, que de hecho no es tal?

Antes de juzgar la pertinencia de estas objeciones, tenemos todavia que explorar otras características sobre el recuerdo de sueños, que, al parecer, es el único acceso que tenemos a los sueños mismos (caso de existir algo asi). Bien podría suceder que este puente rememorativo no fuera tal, que fuera un falso puente, o que los sueños no fueran sino el puente mismo (que soñar fuera lógicamente equivalente a reportar algo que llamamos sueños), pero antes de decidir sobre esto es preciso que investiguemos el problema que se nos presenta, tal y como se nos presenta. De haber aquí un falso problema, éste acabará dejándose ver por sí mismo.

\section{Necesidad de una descripción del tránsito del soñar a la vigilia para esclarecer la pregunta anterior. Descripción del tránsito y esclarecimiento de la pregunta}

Vamos a partir del caso en que recordamos un cierto sueño. ¿Cómo se nos presenta lo recordado? Al contrario de lo que sucede con cualquier recuerdo, en que se re-presentan (vuelven a presentarse) los sentidos de las impresiones que tuvimos en vigilia, en este caso recordamos lo soñado, pero no que soñábamos eso que recordamos. La conciencia de que soñábamos y de que eso que recordamos fue soñado no se origina, no procede de lo soñado: lo soñado no señala su estar siendo soñado ${ }^{6}$. Y sin embargo, recordamos lo soñado como algo soñado. ¿De dónde, entonces, proviene la conciencia de que eso que recordamos fue soñado, si no proviene de lo soñado mismo? Naturalmente, tiene que provenir de la conciencia en su modo de ser de vigilia, que es la única que puede establecer una distinción entre el soñar y la vigilia. Desde el soñar mismo, y correlativamente, desde lo soñado mismo, no hay ninguna alusión a algo así como una vigilia. Veamos, sin embargo, cómo se da este tránsito entre lo uno y lo otro, ateniéndonos a lo que sugieren las líneas anteriores.

El hecho de que podamos recordar lo que soñábamos y de que, en general, podamos notar en ello la total ausencia de marcas que indiquen que se trata de un sueño, seña- 
la que lo soñado estaba siendo soñado sin que hubiera conciencia de estar siendo soñado. Sin embargo, la conciencia de vigilia consigue recordar esto, es decir, hacerlo consciente como un recuerdo y no como una fantasía, y además, recordarlo como algo que fue soñado. Si hemos de confiar en que a veces conseguimos recordar lo que efectivamente hemos soñado, tenemos que suponer que lo soñado ha estado presente para la conciencia de vigilia, a fin de que ella pueda luego re-presentarlo. Pero, ¿cómo se concilia el hecho de que al soñar no haya conciencia de estar soñando (lo que indicaría una especie de hermetismo entre la conciencia que sueña y lo soñado), con el hecho de que lo soñado deba hacerse presente para la conciencia de vigilia (lo que, según parece, rompe el hermetismo del soñar, su absoluto repliegue sobre sí mismo)?

Ante todo, no debemos olvidar que a la hora de describir el pasaje del soñar a la vigilia, estamos describiendo un tránsito, en el cual la tendencia apunta hacia el despertar del yo, esto es, hacia la plena actividad de un yo despierto. Esto sugiere que ha de haber diversas fases en esa transición y que, conforme las fases van realizándose, el nivel de actividad del yo de vigilia va incrementándose, ya sea que esto se dé de manera más gradual o más abrupta. Por eso, conviene, antes de continuar, hacer algunas observaciones sobre los niveles de actividad del yo de la vigilia.

El yo de la vigilia suele estar ocupado en esto y aquello; se dirige aprehensivamente, ya a este objeto (en sentido amplio), ya a este otro. $Y$ si bien este dirigirse aprehensivo hace que el resto de los objetos que se le presentan no goce de semejante atención, y no sea, por lo tanto, activamente aprehendido, no por ello deja el yo de captarlos -siempre que esos otros objetos estén dentro de los confines de lo perceptible. Puede un estímulo proveniente de ese "paisaje de fondo" solicitar la atención del yo, y el yo ceder, y pasar ahora a dirigirse aprehensivamente hacia aquello que llama (una luz que se enciende, un susurro que persiste, etcétera) o no. A este captar no-aprehensivo, le llama Husserl receptividad ${ }^{\prime}$. Así, pues, yo puedo viajar en metro e intentar sustraerme del hacinamiento, el calor, el fastidio, imaginando un sinfín de cosas y absorbiéndome en mis fantasías. Pero por muy intensa, por muy vivaz que sea mi actividad imaginativa, no dejo de tener conciencia, si bien por momentos no del todo expresa, de estar viajando en metro. Tengo, en otras palabras, conciencia del mundo que me circunda, de mi entorno: mi receptividad lo percibe. Por eso dice Husserl que la receptividad es el nivel ínfimo de la actividad del yo ${ }^{8}$.

Contrariamente a lo que sucede con la imaginación, en la cual el yo se dirige aprehensivamente hacia lo imaginado, mientras percibe (capta) todavía el entorno, en el soñar no hay semejante receptividad del yo hacia el entorno que rodea al durmiente ${ }^{9}$. No se da el caso de que yo sueñe y perciba, a la vez, las paredes de mi cuarto, ni siquiera en términos de receptividad. En sueños, no hay conciencia de otro tiempo ni otra espacialidad más que la espaciotemporalidad que el sueño mismo presenta, es decir, una cuasi-espacio-temporalidad. ¿Cómo llega a ser posible, entonces, que este cuasi-mundo ${ }^{10}$, replegado sobre sí mismo, sea luego recordado desde mi vigilia -vigilia de la que el sueño era totalmente "inconsciente"-, y adquiera, con ello, el carácter de sueño?

El motivo por el cual conseguimos recordar los sueños, sin que lo soñado se presente a sí mismo como algo susceptible de ser diferenciado de la vigilia, sino como un "mundo cerrado y absoluto", y que a la vez podamos recordarlo "desde fuera", como sueño, tiene que radicar en el hecho de que durante la primera fase del despertar coexistan lo soñado con la receptividad del yo. Es sólo que aquí la receptividad no percibe el entorno espacio-temporal donde el cuerpo reposa, sino lo único que puede percibir entonces, que es lo primero que le sale al encuentro: el sueño que está teniendo lugar. Por decirlo toscamente: cuando la conciencia de vigilia "entreabre los ojos" (no los ojos físicos, por supuesto), se encuentra con algún sueño y sólo puede, de momento, "recibirlo", captarlo de modo no aprehensivo ${ }^{11}$.

Esto permite explicar cómo es que recordamos los sueños y cómo no se da el problema insinuado hacia el comienzo, a saber, que hablar de recordar sueños podría entrañar un sinsentido (o una ilusión), pues recordar implica re-presentar algo originariamente percibido en el pasado, cuando, según parecía, la conciencia de vigilia no podía haber percibido lo soñado.

Antes de continuar describiendo el tránsito, es preciso observar que la breve descripción anterior abre de inmediato la posibilidad de pensar las cosas de un modo algo distinto a como ha sido sugerido. A partir de lo anterior, bien podría afirmarse que toda vez que se sueña, sea esto poco antes 
de despertar, o bien, en medio de la noche, la conciencia de vigilia capta, "recibe" el sueño; que la receptividad del yo percibe lo soñado y que esto es esencial al soñar mismo. Por lo tanto, la tendencia hacia el despertar del yo no se iniciaria con un despertar de su receptividad (esto ya sería algo propio del soñar), sino en la fase que a continuación describiré. Más adelante discutiré esto, defendiendo que lo soñado no guarda ninguna dependencia lógica con respecto a esta receptividad, razón por la cual no tenemos ningún motivo para considerarla esencial al soñar. Pero todavía es preciso avanzar más en las descripciones. Asumiré, por tanto, que la primera fase del despertar del yo de vigilia se da con la reactivación de su nivel ínfimo de actividad, la receptividad, y que es el encuentro de esa "pura receptividad", bien con un sueño que estaba teniendo lugar, bien con uno que comienza durante esa fase, lo que determina que lo soñado pueda ser recordado en plena vigilia. Llamo a esta fase, fase receptiva (FR). Con todo, FR no ha sido adecuadamente descrita, en la medida en que permanece vaga la noción de una "pura receptividad". (Aclaro, desde ya, que la expresión no se refiere a la receptividad del yo puro ni a nada parecido a esto.) Es preciso esclarecer este concepto.

El dominio que abarca la receptividad del yo de vigilia se determina de un modo negativo: comprende, dentro del campo de lo perceptible, todo aquello que el yo no está aprehendiendo. Hablar, entonces, de una pura receptividad, en la que no hay, concomitantemente, un yo aprehensivo, supone dos cosas: (i) que todo lo que se presenta es captado, parejamente, de modo no aprehensivo; y (ii) que no hay nada siquiera captable fuera de lo que efectivamente es captado. Veamos esto último.

Cuando estamos despiertos, dirigidos hacia algo, somos conscientes de que, aparte de aquello a lo que estamos dirigidos aprehensivamente, hay otras cosas (tómese "cosas" en sentido amplio); pero estamos conscientes de esas otras cosas en un nivel inferior de actividad y es a eso a lo que llamamos receptividad. En cambio, en la pura receptividad, no hay un nivel inferior de actividad, porque ella es ya el nivel ínfimo. Lo soñado es percibido de tal modo que no se deja ver nada aparte de lo que se muestra en sueños; no es posible, en esta fase, adivinar que hay un más-allá-deIo-soñado, una vigilia. Pero no estamos aquí, tampoco, en la pasividad del yo, en el "inconsciente", sino que se trata de un percibir la actividad inconsciente (actividad de la pasividad); es sólo que este peculiar percibir está todavía inmerso en lo percibido. Desde la inmersión con que la pura receptividad percibe, no es posible que el polo yoico, que así percibe, advierta los confines de lo soñado (no hay nada captable, en un nivel inferior, más allá de lo soñado: no se intuyen límites); en consecuencia, es incapaz de percibir su no-identificación con el yo que sueña, aun cuando no haya semejante identificación. Así es como la pura receptividad de algo que no es todavía el yo plenamente constituido de la vigilia, sino un polo yoico que tiende a constituirse en tal (una pre-conciencia de vigilia), así, digo, es como la pura receptividad tiende el puente entre el soñar y la vigilia.

La evidencia en que se apoya lo anterior es parcialmente directa y parcialmente indirecta. La parte que atañe a la evidencia directa surge de la autoobservación que el investigador hace en el umbral entre el soñar y la vigilia. Toda descripción fenomenológica debe beber en esta autoobservación, en primera instancia. Mi parecer es que, cualquiera que se tome este trabajo, llegará a una descripción semejante a la que he ensayado. La evidencia indirecta la proporciona el hecho de que, de no admitir una fase de pura receptividad (o algo muy parecido), no sería posible explicar, o bien cómo es que recordamos los sueños (cómo es que la conciencia de vigilia puede re-presentar lo soñado si ella no lo ha percibido), o bien cómo es que los sueños pueden ser recordados en vigilia qua sueños, siendo que lo soñado muestra ser completamente hermético e "inconsciente" de algo así como una vigilia. Esto sugiere que el sueño y la conciencia de vigilia deben coexistir en alguna fase, de tal modo que la conciencia de vigilia sea una pre-conciencia de vigilia, una conciencia en nada invasiva, y sin embargo, ya más propia del modo de ser de la vigilia que de la conciencia que sueña. [De otro lado, las descripciones pueden resultar quizá oscuras, pero cuando se trata de identificar qué hay todavía de oruga, y qué ya de mariposa, el lenguaje se ve necesariamente forzado a concebir oruriposas (= pura receptividad).]

Ahora bien, en FR las funciones más altas de la conciencia de vigilia todavía no se han activado; pero desde que inicia el despertar de la conciencia de vigilia (o de la conciencia a la vigilia), se inicia también la tendencia que le es propia y que consiste en imponerse a través de una reactivación de todos sus niveles. La pura receptividad, inmersa hasta ahora en los sentidos oníricos que se le presentaban, comienza a ceder a un incremento de la actividad del yo, en el que 
se introduce la autoconciencia que es propia del modo de ser de la vigilia. Esta autoconciencia se muestra como la conciencia de un "regreso a lo mismo"12, a la continuación de la vida que había quedado suspensa durante el reposo, al mismo yo empírico que ayer se acostaba a dormir con tales y cuales preocupaciones y al que hoy le aguardan tales y cuales otras. Así, lo recién experimentado por la receptividad, que aún no tenía marcas de ser onírico, pasa a ser aprehendido por la conciencia de vigilia (consciente ya de sí misma, de la vigilia a la que ha regresado) como "sueño", y más concretamente, como lo recién soñado. Es sólo en esta fase, en la que la actividad del yo se vuelve ya aprehensiva, cuando se adquiere la conciencia de que lo captado fue soñado; antes, no había semejante marca.

\section{Determinación negativa del carácter esencial del soñar, a la luz de los resultados alcanzados. Evaluación de la autonomía del soñar con respecto a la vigilia}

Lo anterior muestra cómo lo soñado en cuanto tal, antes de ser marcado desde la vigilia, es originariamente algo por completo indiferente a ella, abismado de ella, "inconsciente" de ella en cuanto vigilia. Lo SOÑADO ES, PARA EL SOÑANTE, ${ }_{A B S O L U T O}{ }^{13}$ (tal como lo expresa el testimonio de la memoria, en que lo soñado no se muestra a sí mismo señalando su ser-soñado); sólo adquiere un carácter relativo cuando la conciencia de vigilia, habiendo ya ganado su actividad aprehensiva, lo relaciona (lo compara tácitamente) consigo misma y establece así la diferencia.

Podemos, entonces, a partir de lo anterior, cuya evidencia primera es lo soñado, aventurar el carácter ontológico del soñar como un modo de ser de la conciencia que implica, por esencia, la cancelación del modo de ser de la conciencia de vigilia ${ }^{14}$.

Esta conclusión parece hasta cierto punto trivial y el vocero del sentido común, a menudo receloso del filósofo, vendrá y dirá: ¡Tanto esfuerzo para decir lo que ya todos sabemos: que cuando soñamos no estamos despiertos! Pero el filósofo, desconfiado a su vez del sentido común, podrá objetar, no sólo que el sentido común pierde de vista los problemas propios de afirmar tan alegremente una cosa así, sino también, que él mismo (el filósofo) no está todavía seguro de si todo soñar no implicará algún mínimo umbral de vigilia -lo que hemos Ilamado una pura receptividad-, con lo cual la referida cancelación debe ser exactamente delimitada. Al soñar, ¿se cancela por completo la conciencia de vigilia?, ¿se cancela casi por completo? Lo que aqui está en juego es nada menos que la exacta determinación de la autonomía del soñar.

Nadie pone en cuestión que las imágenes de los sueños toman su "materia prima" de las impresiones de la vigilia. Pero, más allá de esto, sería muy distinto concebir el soñar como algo que sólo puede darse cuando hay, a la par, una conciencia o pre-conciencia de vigilia, que concebirlo como algo que puede darse con independencia de esto último. Resulta claro que la conciencia de vigilia no depende en absoluto, para ser (no es esencial a su modo de ser), de que haya a la par una conciencia soñante; al contrario, esto último amenaza con cancelarla. Con lo cual, si resulta que es esencial al soñar la participación de algún modo de vigilia o pre-vigilia, será claro que el soñar, en su darse mismo, se funda en la vigilia, más bien que cancelarla; y que, por lo tanto, tendría algún sentido subsumir -con los recaudos del caso- alguna teleología del soñar a una teleología de la vigilia, como implícitamente se hace desde la onirocrítica más primitiva hasta el psicoanálisis. De ahí que sea necesario estudiar esta primera determinación negativa del soñar ${ }^{15}$, preguntándose en qué medida el soñar exige una cancelación del modo de ser de la conciencia de vigilia y hasta dónde Ilega su autonomía con respecto a esta última.

No parece haber mayores dificultades para determinar esto, una vez hechas las descripciones anteriores. Lo que queda en evidencia es que no hay una dependencia lógica de lo soñado con respecto a la receptividad de FR: lo soñado no depende, para darse, de ninguna instancia de vigilia o pre-vigilia; sólo depende de esta clase de instancia para ser recordado. La única dependencia lógica que guarda lo soñado es con respecto a la conciencia que sueña, que no es sino la conciencia pasiva: es en ella donde lo soñado se muestra, independientemente de si hay una pura receptividad que alcance a percibirlo o no.

El hermetismo que deja ver lo soñado cuando alcanzamos a recordarlo, su completa falta de indicaciones con respecto a su ser-soñado y a la posibilidad de una distinción entre el soñar y la vigilia, muestra, en efecto, el hermetismo originario que es propio de la "vida onírica": de ella sólo podemos decir, negativamente, que se repliega sobre sí

ARBOR CLXXXV 736 marzo-abril [2009] 403-426 ISSN: 0210-1963

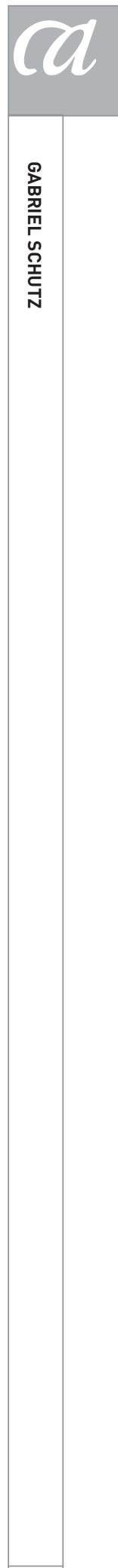


misma y que es in-consciente, es decir, una vida que, para "vivir" (desplegarse), no precisa de una conciencia activa, ni aun de una pre-conciencia, al estilo de la pura receptividad.

Con esto se afirma la independencia lógica del soñar con respecto a la vigilia, en el sentido de que para soñar no tiene que haber una "conciencia testigo" de vigilia (no se afirma, en cambio, ni podría hacerse, que pueda haber un soñar, en general, sin que haya una vigilia en general). Pero también queda de manifiesto que el soñar impone, de manera esencial, una cancelación de la conciencia de vigilia, y contra esto no atenta en nada que podamos recordar algunos de nuestros sueños (es decir, que en estos casos si haya una pre-conciencia de vigilia). Porque los sueños que se recuerdan son apenas el caso límite dentro del espacio lógico de los sueños posibles. Este espacio incluye a priori la posibilidad de todos los sueños soñados de los que no conservamos, una vez despiertos, el menor recuerdo ${ }^{16}$, siquiera de haber sido soñados. El carácter de caso límite de los sueños que recordamos viene dado por el hecho de que ellos son recordables precisamente por darse en el límite: en el límite en que el soñar y la vigilia se tocan -de no haber un punto de contacto, esos sueños no serían nunca recordables.

[Dados los motivos teóricos sugeridos hacia el comienzo, la investigación no podía comenzar sino por la descripción de un límite -umbral- y esto fue lo que nos condujo a introducir el concepto de una pura receptividad que percibe lo soñado. Para que este concepto describiera adecuadamente el tránsito entre el soñar y la vigilia, debía ser él mismo un concepto límite (una "oruriposa"), que mostrara su serlímite. Pero para que un límite se muestre como tal, debe indicar, necesariamente, qué es lo que queda delimitado "a uno y otro lado", haciendo ver la diferencia entre lo uno y lo otro (de no haberla, el límite desaparecería como tal). Por eso, la descripción de la pura receptividad ya sugería los caracteres, los modos de ser, de lo que estaba "a uno y otro lado" -el soñar y la vigilia-, "antes" de tocarse en el límite. Es ésta la razón de que pueda, desde el límite, iniciarse una fenomenología negativa de los sueños: el caso límite señala necesariamente el caso general.]

Con esto asentamos, negativamente, el carácter del soñar como un modo de ser de la conciencia que implica la cancelación del modo de ser de la conciencia de vigilia.

\subsection{Los sueños que muestran que alguien sueña y "Esto es un sueño"}

A los resultados anteriores le salen al paso dos casos peculiares, que podrian poner en entredicho la esencial cancelación que el soñar impone al modo de ser de la vigilia. Uno de ellos se da cuando el sueño presenta la situación de alguien que sueña (un soñar adentro del sueño); con esto, parecería que se presentara, en sueños, una distinción entre el soñar y el no-soñar, distinción que habíamos negado antes. Pero aquí no hay realmente un problema, y esto porque la distinción es interna al sueño, no externa a éste. El sueño que yo sueño (nivel 1) muestra a alguien que sueña (cuyo sueño sería el nivel 2), pero no muestra que haya una vigilia más allá de sí mismo, un mundo que incluya este sueño (nivel 1) que yo estoy soñando ${ }^{17}$. De modo que la caracterización anterior no corre peligro: la conciencia de vigilia sigue igualmente cancelada en estos casos.

Más complicado resulta, al parecer, el caso en que el sueño denuncia su carácter onírico y somos conscientes, soñando, de algo así como "Esto es un sueño". Lo primero que debemos notar aquí es que si recordamos este tipo de sueños es porque ha habido una fase receptiva, una pura receptividad que, por así decir, tomó el registro, con lo cual ya estamos dentro de un caso límite. Pero no hay que descansarse en ello y sentir que con la apelación al límite quedamos exentos de dar alguna explicación, entre otras cosas porque se trata de un caso límite especialmente interesante.

Tenemos aquí dos posibilidades: o bien la denuncia "Esto es un sueño" no se incluye a sí misma, o bien se incluye. Es decir, si estoy soñando con un gato que me habla y me ofrece su amistad, y entonces se denuncia que eso es un sueño, la denuncia misma puede aparecer como no siendo ella misma soñada, o bien, como queriendo decir "Esto (el gato parlante y amistoso) es un sueño -y 'yo' también lo soy". Si la denuncia sólo señala al gato soñado y escamotea que ella misma está siendo soñada, entonces todo lo que sucede es que sueño con un gato así y así, y sueño con que me digo que el gato así y así es un sueño. Estamos, pues, nuevamente en el caso anterior de un sueño dentro de otro sueño, con la única diferencia de que aquí el soñante que sueña con el gato permanece indeterminado. Si, en cambio, "Esto es un sueño" alude a mi propio soñar, las posibilidades son, o bien que sueño con que todo lo que 
estoy soñando está siendo soñado por mí, que es, otra vez, un caso del tipo sueño-dentro-del-sueño, sólo que aquí el nivel 1 y el nivel 2 se espejan entre sí (myse en abîme) ${ }^{18}$; 0 bien "Esto es un sueño" es algo así como una infiltración de la conciencia de vigilia en medio del sueño. Esta última posibilidad tampoco constituye una amenaza a la esencial cancelación de la conciencia de vigilia, por parte del sueño, pues la denuncia no proviene de lo soñado mismo, sino de una vigilia infiltrada. Se trata, simplemente, de un caso límite peculiar. Con todo, dada su peculiaridad, conviene ensayar una descripción para intentar esclarecerlo ${ }^{19}$.

Si estoy soñando un sueño que luego conseguiré recordar, entonces mi sueño está transcurriendo en FR, y por lo tanto, coexisten el soñar y lo que hemos llamado la pura receptividad de una pre-conciencia de vigilia. En el tránsito de esta fase hacia la siguiente, con vistas al despertar pleno del yo, la receptividad va cediendo a un incremento de la actividad del yo de vigilia, hasta que éste alcanza su plenitud. Sin embargo, en estos casos, el progreso de esta segunda fase se interrumpe. En general, la ganancia de actividad del yo de vigilia trae como consecuencia que la receptividad del yo deje de ser una pura receptividad de lo soñado y capte ahora algo más-allá-de-lo-soñado, algo indeterminado, o sólo determinado negativamente como lo no-sueño, a cuya captación sucede la captación de un regreso ${ }^{20}$ (con lo cual lo soñado comienza a desaparecer). Este captar de la vigilia, o más bien, la vigilia captada de modo especialmente indeterminado, solicita al yo para que éste se vuelva aprehensivamente hacia ella, cosa que normalmente sucede: es entonces cuando el yo despierta en sentido propio (pienso lo que hay que hacer en el día, o recuerdo algo del día anterior, o miro la luz que se filtra por la ventana del cuarto, en fin, aprehendo algo del mundo de la vigilia). En los casos del tipo "Estoy soñando", entendidos como una infiltración de la vigilia, la pura receptividad da paso a una receptividad que advierte lo más-allá-de-losoñado, pero en lugar de que la actividad aprehensiva del yo inicie aquí con la captación del regreso y "acompañe su curso", apuntando hacia el mundo de vigilia, el yo se vuelve hacia lo soñado, que todavía está siendo captado (si bien va tendiendo ya a desaparecer), y lo aprehende como tema. La vigilia no ha sido activamente aprehendida esta vez, pero sí se ha captado un ámbito de no-sueño, que le basta al yo, vuelto hacia lo soñado, para tener la conciencia de "Esto es un sueño". A menudo esta "marcha atrás" del proceso del despertar hace que el yo vuelva a caer dormido y el sueño retome su curso (u otro curso), y así es como tenemos luego la impresión de que el sueño mismo "se dio cuenta" de estar soñando, cuando, bien vistas las cosas, se trató de un despertar que se desdijo en medio y, por así decir, volvió sobre sus pasos (y esto no podrá ser recordado jamás como un despertar, pues el yo nunca alcanzó a captar "el regreso" a la vigilia). Así, pues, la denuncia "Esto es un sueño", en la más problemática de sus posibilidades, no proviene de lo soñado, no fisura su hermetismo a través de una extravagante referencia a si mismo, sino que procede de un despertar trunco, es decir, de la conciencia de vigilia. Por lo tanto, si la descripción anterior es correcta, éste no es sino un caso peculiar dentro de la clase de los casos límite, en los cuales el soñar y la vigilia se tocan.

Hechas estas aclaraciones, es preciso seguir adelante con lo que nos habíamos propuesto, que era evaluar si los sueños recordados que resultan del tránsito del soñar a la vigilia constituyen una evidencia fiable sobre la cual trabajar o no; si son fiables, resta determinar en qué medida y bajo qué condiciones se alcanza la máxima fiabilidad posible, pues ésta sería nuestra mejor evidencia fenomenológica.

\section{Determinación de la mejor evidencia posible y sugerencia sobre el camino teórico a seguir}

Los resultados alcanzados señalan que es condición necesaria, pero no suficiente, para la rememorabilidad de cualquier sueño, que haya habido conciencia activa (receptiva) de éste, es decir, que haya habido una conciencia de lo onírico que sea ya la conciencia (o pre-conciencia) de vigilia. Esto implica, como se señaló antes, que recordamos únicamente aquellos sueños en que fuimos activamente (receptivamente) conscientes de lo soñado. Llamo a estos sueños, sueños de umbral.

Ya se ha dicho que el espacio lógico de los sueños rebasa con mucho los sueños de umbral y que éstos son sólo los que se encuentran en el límite de ese espacio ${ }^{21}$. En consecuencia, no debemos caer en la tentación de reducir los sueños en general a los sueños de umbral. Sin embargo, sí podemos decir que los únicos sueños de que tenemos experiencia son los sueños de umbrap2. Lo que debemos examinar ahora es en qué medida nos es posible recordar esos sueños una vez que no estamos ya en el umbral, sino cuando la conciencia de vigilia se ha impuesto por

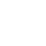


completo; esa medida indica la medida de la fiabilidad de nuestra evidencia.

En el tránsito entre el soñar y la vigilia, lo soñado sufre ciertas modificaciones que vienen impuestas por el propio modo de ser del tránsito. Ya vimos antes que lo soñado no se muestra, originariamente, como soñado (a la conciencia soñante), y que adquiere este carácter una vez que la conciencia se encuentra en condiciones de hacer la distinción entre sueño y vigilia; es decir, siendo ya una plena conciencia de vigilia que se dirige, aprehensivamente, hacia lo recién percibido (por la pura receptividad) -que se le aparece ahora como recién soñado ${ }^{23}$. El tránsito mismo impone esta marca, que originalmente no existía. Y tal vez haya otras condiciones que el tránsito impone a lo soñado para que éste pueda llegar a ser recordado en vigilia. El mejor recuerdo posible de un sueño no estará exento de estas marcas, inherentes al transitar mismo, sino que será el que, por así decir, atraviese el umbral sin haber sucumbido a adulteraciones, extravíos o modificaciones evitables. Por eso, para determinar nuestra mejor evidencia, nuestro recuerdo-de-sueño más prístino, debemos estudiar antes todo lo que amenaza su preservación a lo largo del tránsito. Se trata, pues, de determinar negativamente nuestra mejor evidencia posible; luego habrá que ver qué determinaciones positivas presenta, si es que esto puede hacerse.

El punto de partida que parece más claro es estudiar el olvido de los sueños; pues, a fin de cuentas, nuestra mejor evidencia fenomenológica será el mejor tipo de recuerdode-sueño, y ése es aquel que sortea todos los posibles olvidos que amenacen con extraviar algunas de sus características, cualidades o rasgos, si no al sueño todo.

\subsection{Cómo y por qué se olvidan los sueños (estudio negativo de las condiciones de su evocabilidad)}

En relación al olvido de los sueños, llama poderosamente la atención que seamos tan proclives a olvidarlos -si no a todos, a muchos de ellos-, así como la facilidad con que se esfuman. La descripción del umbral entre el soñar y la vigilia partía del caso en el que se recuerda qué fue lo que se ha soñado -sea (i)-, que sería, en términos generales, la mejor situación posible. A ésta le suceden aquellos casos en que se recuerda que se ha soñado, pero no lo soñado (ii); $y$, siempre con este grado de generalidad, el caso en que no se recuerda siquiera si se ha soñado o no (iii). ¿Nos permite la descripción del umbral dar cuenta de estos dos últimos casos, que pertenecen ya a un ámbito de "olvido"?24.

Comencemos con (ii). Si se recuerda que se ha soñado algo es porque se recuerda que en algún momento hubo conciencia de lo soñado. En FR se activa únicamente la pura receptividad, que capta el sueño que se está soñando. Hasta aquí estamos en la misma situación que en (i). En aquel caso, el ingreso a la segunda fase del despertar trae aparejada la actividad aprehensiva del yo, que estaba ausente en la pura receptividad de FR. El yo, consciente ya de estar despierto ${ }^{25}$, se dirige hacia lo recién percibido, marcándolo eo ipso como "sueño", y pudiendo, si lo desea, aprovechar la frescura con que se muestra lo recién soñado para repasarlo y fijarlo. En el caso (ii), sin embargo, en lugar de dirigirse a la "reconstrucción" de lo recién soñado, la conciencia de vigilia se impone de tal modo que su actividad se dirige de manera franca a la realización de su tendencia, esto es, a alcanzar la plenitud de su ser-vigilia. No obstante, por un momento la conciencia de estar despertando ha dirigido un rayo de atención al hecho de tener todavía ante sí una "imagen onírica (o acaso, una serie de imágenes)". En ese breve dirigirse a la imagen, la atención repara fugazmente en ella, pero la tendencia a seguir realizando el despertar es tan poderosa, que ese breve reparar no basta para aprehender la imagen misma; todo lo que se conserva de ella es la marca de imagen onírica (de "sueño") hecha en ese instante por la conciencia de vigilia ${ }^{26}$. En cuanto a los sentidos oníricos percibidos en FR (el último de los cuales era esa imagen), éstos no alcanzaron nunca a ser activamente aprehendidos, pues, a diferencia de lo que sucedía en (i), aquí el yo despierto no se dirige con vistas a reconstruir o repasar lo soñado. Así, una vez que se ha impuesto la plena conciencia de vigilia, es posible recordar que se ha soñado, pero no qué fue lo soñado, pues nada de lo que ahora se halla presente a la conciencia lo "recuerda": nada ahora es susceptible de ser asociado con lo soñado ${ }^{27}$.

El caso (iii) admite dos posibilidades: o bien, en FR la pura receptividad no encuentra "ante si" un sueño ${ }^{28}$, con lo cual, una vez despiertos, no podemos decir si hemos soñado o no (quizá aquí no cabe hablar de "olvido" en sentido estricto); o bien, lo encuentra, pero en la segunda fase del despertar la conciencia de vigilia se impone de un modo todavía más abrupto y poderoso que en (ii); esto es, la conciencia se dirige tan derechamente hacia la consumación del 
despertar, que no sólo deja atrás la última imagen onírica, fugazmente aprehendida, sino el mismo hecho de haberla aprehendido. No hay ningún detenimiento, el yo se absorbe en la vigilia sin "volver la vista atrás". Si se le pregunta, poco después, si ha soñado algo en la noche, será ya tarde para responder que sí o que no.

Ahora bien, en (ii) y en la segunda posibilidad de (iii), el hecho de que el sueño no alcance a ser recordado, una vez que el yo está despierto, obedece a que no se dan dos condiciones necesarias para la evocabilidad en general. La primera de estas condiciones es empírica: puede darse 0 no; si se da, el sueño será recordado; si no, no. Pero puesto que en los dos casos señalados el sueño es olvidado (si bien puede todavía ser recordado más tarde), se deduce que la condición empírica no se da. Esta condición es la de nexos asociativos capaces de "despertar" lo soñado. En los casos anteriores, nada de lo que se le presenta a la conciencia ya despierta evoca o es asociable con lo soñado (ninguno de mis pensamientos, sensaciones, nada en el paisaje de objetos de mi pieza me recuerda al gato parlante que había soñado). No hablamos aquí de un activo esfuerzo rememorativo, sino de las asociaciones pasivas -en que se fundan las asociaciones activas-, que no encuentran, en estos dos casos, "materia" en el presente vivo, como para tender el nexo asociativo con lo soñado y así "despertarlo" otra vez. Esto sí se daría si, por ejemplo, mientras estoy tendido en la cama, restregándome los ojos y pensando vagamente en las ocupaciones del día, escucho al gato de la vecina y se me impone instantáneamente el recuerdo de haber soñado con un gato, sin que yo haya estado envuelto o comprometido en esta asociación.

La otra condición cuyo no darse determina que el sueño termine por ser olvidado, no es empírica sino ontológica. Es ella la responsable de que, salvo que el yo que despierta se vuelva aprehensivamente, y con un interés resuelto, hacia lo soñado, esto último acabe perdiéndose (y quede a merced de posibles asociaciones pasivas para ser recordado). Aquí lo que falta no es un nexo asociativo, sino un nexo temporal, y esto, precisamente, por el modo de ser del soñar, que impone la cancelación del modo de ser de la conciencia de vigilia. Al quedar cancelada la vigilia, queda suspendida la conciencia del tiempo uno, la unidad del flujo temporal: los sueños, lo mismo que los objetos de la imaginación, son extemporáneos, o, como suele decir Husserl, cuasi-temporales.
En efecto, aunque los objetos de la imaginación se presentan con determinaciones temporales, no guardan conexiones que puedan ser adscritas entre unos y otros en un tiempo único. Puedo, por supuesto, localizar si he imaginado esto o aquello antes o después, pero no se habla aquí de los actos de imaginar sino de las relaciones temporales entre los propios objetos imaginados. Dice Husserl:

El centauro que me estoy imaginando ahora y un hipopótamo que me había imaginado antes $y$, por otra parte, la mesa que estoy percibiendo ahora mismo, no guardan conexión alguna entre sí, es decir, no tienen unas respecto de otras ninguna situación temporal. Si todas las experiencias, las presentes y las pasadas, se integran para el nexo de una experiencia; y si tienen ahí un orden temporal claro del antes, del después y del simultáneamente en el tiempo absoluto, eso no es válido de las objetividades de la fantasía; el centauro no es ni antes ni después que el hipopótamo o que la mesa que percibo ahora ${ }^{29}$.

Con los objetos del soñar sucede lo mismo, con la importante diferencia de que, mientras imagino, tengo todavía conciencia (receptiva) del tiempo uno en el que yo imagino, mientras que en sueños, no hay semejante conciencia. Por lo tanto, a menos que el yo haga un esfuerzo activo por insertar lo soñado dentro de los nexos temporales del tiempo de vigilia (y esto sólo puede hacerlo en la fase final del umbral de duermevela, aquí, la segunda fase), lo soñado quedará "fuera de este mundo", replegado en el hermetismo de la pasividad a que pertenece originariamente.

Intentaré explicarme mejor con lo siguiente. Si yo deseo recordar algo de mi niñez, con seguridad no me será empíricamente posible alcanzar ese recuerdo si decido hacerlo recorriendo retrospectivamente la serie de todo lo vivido, desde el ahora hasta entonces (a Tristram Shandy le toma un año escribir un día de su vida). Pero es teóricamente posible hacer ese recorrido, porque el sentido de cada vivencia vivida está sintéticamente ligado con los sentidos de las vivencias "contiguas" ( $y$, de manera mediata, con los sentidos de todas las vivencias), de suerte que uno conduce al siguiente y así sucesivamente. En el caso de los sueños que no han sido "insertados" o ligados, de manera más o menos deliberada, dentro de la situación temporal de la vigilia, no hay modo de que este recorrido retrospectivo, paso a paso, alcance lo soñado. Pongamos que estoy ahora incorporado en la cama y decido iniciar ese recorrido (esto sólo tendría sentido para

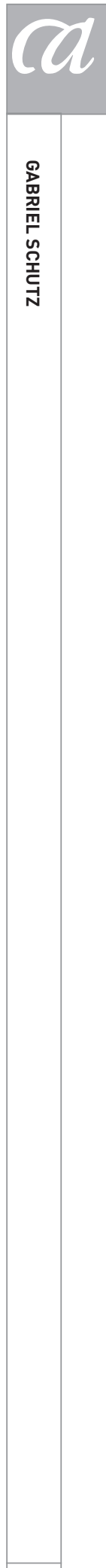


el caso (ii), en que se recuerda, al menos, que se ha soñado). Me recuerdo a mí mismo incorporándome, recuerdo luego la cuenta de tres ("A la cuenta de tres me levanto: Uno, dos... y... mmh, dos y medio, dos y tres cuartos... ¡Ya, tres!"), el entreabrir de los ojos, algunos pensamientos; recuerdo estar todavía con los ojos cerrados y pensar: "Ah, sé que soñé algo, pero no recuerdo qué era", de modo que me lanzo a seguir la retrospectiva: recuerdo la pesantez del cuerpo, el calor de las mantas y trato de seguir, pero ya no hay NADA: el recuerdo del calor de las mantas no me va a conducir al recuerdo del gato que me hablaba, porque ese gato no era de este mundo; y no era de este mundo, porque el yo que lo soñaba estaba, TODo É (a diferencia del yo que imagina) fuera del tiempo del mundo. Por otro lado, la pura receptividad de FR no constituía todavía una aprehensión de lo soñado, capaz de insertarlo en el tiempo del mundo, que es como decir, el tiempo de la vigilia. Esto sólo puede hacerlo la actividad aprehensiva del yo, que se suma en la fase siguiente. Si no lo ha hecho, el sueño sólo podrá ser recordado por obra de una fortuita asociación, que bien puede darse mucho después de haber despertado. Este caso merece unas palabras, pero antes quiero enfatizar, una última vez, cómo el carácter ontológico del soñar es el que, por sí solo, acota ostensiblemente la posibilidad de recordar nuestros sueños.

Con respecto al caso recién sugerido, es aquel que se da cuando, varias horas después de haber despertado, y estando uno ocupado en sus asuntos, se presenta algo -quizá algo percibido en el entorno, o una palabra escuchada o leída o lo que fuere- que le hace recordar a uno que ha soñado con algo semejante (un compañero de trabajo habla de fútbol y recordamos haber soñado con un estadio; vemos un gato y recordamos haber soñado con un gato). El puente asociativo que faltaba en (ii) y en (iii) se ha tendido ahora. A esta altura parece claro que el puente no se tiende desde el presente vivo hacia el "oscuro reino de los sueños"; lo que consigue ser evocado, por medio de esta asociación, no es sino aquello que se ha presentado en la primera fase del despertar (consumado o trunco, como en los casos del tipo "Esto es un sueño"), cuando la conciencia de vigilia era una pura receptividad de lo soñado. Ninguna asociación podrá conducirnos a sueños que hayan sido como islas en medio del vasto océano de la noche, sueños sin el silencioso atestiguar de la vigilia, porque esto supondría poder recordar lo que nunca antes ha estado presente a la conciencia que recuerda, lo cual es manifiestamente una contradicción.
Con esto, dejamos atrás el aspecto que atañe al olvido de los sueños ${ }^{30}$.

\subsection{La aprehensión de los sueños: problemas e indicaciones}

En la sección anterior veiamos que, más allá de las fortuitas asociaciones pasivas, capaces de hacer resurgir o no algo de lo soñado, había una condición ontológica de lo soñado mismo que resultaba desfavorable para su posterior rememoración en vigilia. Desde el soñar y lo soñado no parte nunca una intención con vistas a integrarse en los nexos temporales de la vida despierta, sino que todo el trabajo corre por cuenta del yo de vigilia. Así, pues, la posibilidad de recordar los sueños radica en que, durante la segunda fase del despertar, cuando se reactiva la actividad aprehensiva del yo, éste se dirija hacia lo percibido en $F R$, y lo mantenga asido tanto como le sea posible.

¿Qué sucede en esta segunda etapa del despertar, cuando la conciencia de vigilia se vuelve hacia lo recién soñado? Es evidente que aquí ya no estamos en el soñar mismo y que es en ese volverse del yo despierto, hacia lo recién percibido, que esto último se muestra como "sueño". La conciencia de vigilia distingue ahora un modo de ser que no es el mismo que el suyo, un modo de ser que se muestra como Otro. De este desdoblamiento surge la distinción y la consecuente marca de "sueño". Pero la tendencia de la conciencia de vigilia no es a permanecer vuelta hacia lo recién soñado, sino a responder a la solicitud de un despertar cabal -como si se tratara de un conatus, en sentido spinoziano: la conciencia de vigilia persevera en su ser-vigilia. Estando vuelta hacia lo recién soñado, aun cuando no sucumba de momento a la tendencia hacia el despertar pleno -lo que implica, lógicamente, renunciar a seguir atendiendo el sueño que se desea asir-, la conciencia resiste esta tendencia: es una conciencia en resistencia. La voluntad que la anima a permanecer vuelta hacia lo que acaba de ser soñado se disputa con la voluntad que la rige en cuanto conciencia de vigilia y que la anima a despertar por completo. En esta resistencia, la atención concedida a lo onírico puede comenzar a disiparse (como el calor que disipan las resistencias eléctricas). Es por eso por lo que el esfuerzo por asir lo recién soñado, a menudo conspira contra su propio propósito, si bien es difícil que lo malogre por completo (casi, se diría, que es como cuando nos forzamos a "actuar naturalmente": el esfuerzo conspira contra la naturalidad buscada). 
Si estamos demasiado activamente conscientes de lo recién soñado, estamos demasiado activamente conscientes en general, y este nivel de actividad aprehensiva de la conciencia es ya la imposición del yo de vigilia: lo único que se logra es favorecer la tendencia de la conciencia a alcanzar su plena actividad, su plena "lucidez" de vigilia. No es que el resultado de esto sea un completo olvido de lo que se ha soñado, pero, en general, un procedimiento como el anterior hace que una buena parte de los sentidos oníricos se escurran como arena entre las manos; lo que sobrevive es un puñado, migajas de sueño.

Por otro lado, si el nivel de actividad de la conciencia es muy bajo, su aprehensión de lo soñado comienza también a ceder, y con ella se inicia la tendencia a volver a caer dormidos. Estamos, pues, en un equilibro tremendamente inestable, que, al parecer, está condenado a ser breve: o bien se impone la vigilia, o bien se impone el dormir (con o sin sueños). Si se impone el dormir, hemos perdido la partida y el sueño que se deseaba asir acabará hundiéndose nuevamente junto con la cesación de la actividad del yo de vigilia. Si, por otro lado, la actividad aprehensiva es demasiado intensa, se impone la conciencia de vigilia de un modo que casi hace huir lo que queriamos preservar.

Según parece, el modo idóneo de asir un sueño debe ser tal que haya una actividad sostenida del yo de vigilia, para no caer dormidos, pero a la vez, una actividad que no se intensifique de cara al despertar, sino que se mantenga estable y tan atenuada como sea posible. Es como si intentáramos permanecer pegados al límite entre FR y la fase actual, es decir, TAN CERCA DE SER UNA PURA RECEPTIVIDAD COMO SEA POSIBLE, Sin, por supuesto, recaer en la fase anterior, que significaría el inicio de una franca tendencia hacia el dormir. Se trataria, pues, de retener lo soñado, suspendiendo el progreso de la segunda etapa del despertar, sin que medie una activa resistencia (y esto es lo difícil); como si permaneciéramos orbitando sobre lo soñado bajo una especie de "atención flotante", una aprehensión, en sentido fenomenológico, que fuera no aprehensiva, en sentido coloquial ("Fulano es una persona muy aprehensiva").

El párrafo anterior da indicaciones sobre las mejores condiciones posibles para asir lo soñado $y$, por lo tanto, señala, aunque sin exhaustividad, las condiciones de posibilidad de la mejor evidencia posible. La evidencia es empírica ${ }^{31}$; sus condiciones de posibilidad, no. Estas últimas responden a la descripción fenomenológica del tránsito entre el soñar y la vigilia, descripción que nos ha permitido, además, dar respuesta a una serie de problemas que se presentan en cualquier estudio de los sueños: ¿Por qué olvidamos los sueños? ¿Qué relación guarda el soñar con la vigilia? ¿Qué sucede en los sueños del tipo "Esto es un sueño"?, etc. Pero da la sensación de que este último resultado -la indicación de las condiciones de posibilidad de la mejor evidencia empírica posible- palidece con respecto a los anteriores $y$ es como si uno se dijera:

- Muy bien, supongamos que éstas son las mejores condiciones de posibilidad, que así se obtiene la mejor evidencia posible. ¡¿Y qué?! Supongamos que hago caso de esto último y que, antes de lanzarme a hacer una investigación sobre los sueños, me adiestro en aprehender mis propios sueños, no bien despierto, de tal modo de permanecer en una especie de prolongación inadvertida de la fase receptiva. El resultado es que logro aprehender el sueño sin perder demasiado, o perdiendo tan poco como sea posible. i¿Y esto es todo?!

- Sí, es todo. Pero aún no se ha visto las implicaciones que esto entraña, porque no ha quedado determinado el alcance del "sin perder demasiado" o "perder tan poco como sea posible". Y no puede esto determinarse a menos que veamos todo lo que sí puede perderse. Este extravío no es apenas el olvido, no se agota en que una o varias "partes" del sueño no puedan ser aprehendidas. La "pérdida" más peligrosa es la de todo aquello que originariamente se ofrece en el soñar, todas aquellas "cualidades" y caracteres de lo soñado, que una mala aprehensión ignora, o peor todavía, adultera sin saberlo. $Y$ así es como se habla luego de los sueños, creyendo hablar de ellos, cuando en realidad se habla de algo a lo que se le ha inoculado, de manera inadvertida, el carácter propio de la vigilia.

A continuación, intentaré hacer ver cómo las indicaciones anteriores, no son tanto una recomendación metodológica, con vistas a obtener la mejor "muestra" empírica posible (aunque también son esto), como una clara indicación del camino que debe seguir una teoría de los sueños, a fin de evitar introducir en los sueños mismos determinaciones que no les pertenecen. Ese camino es el de una fenomenología negativa de los sueños.

ARBOR

CLXXXV 736 marzo-abril [2009] 403-426 ISSN: 0210-1963 


\section{Hacia una fenomenología negativa DE LOS SUEÑOS}

\section{Sugerencia sobre los motivos para caracterizar negativamente los sueños}

¿Qué clase de determinaciones ajenas a lo soñado introduce la conciencia de vigilia? ¿Cuáles de ellas son evitables y cuáles no? Por ejemplo, la marca (o el marco) de "sueño" no era algo originario del sueño mismo, sino algo introducido por la conciencia de vigilia; y sin embargo, se trata de una marca necesaria, inevitable. Así, pues, debemos mirar ahora, ya no lo soñado mismo, hasta donde esto es posible, sino cómo es que asimos lo soñado, qué introducimos en él inadvertidamente, etc. Pero esto nos ubica en un círculo problemático: ¿Cómo saber si introducimos en lo soñado determinaciones que le son ajenas, sin haber descrito antes cómo es lo soñado? ¿Y cómo podemos describir lo soñado mismo, asegurándonos de no introducir elementos que le sean ajenos?

Un modo de evitar el círculo, o al menos, de mantenerlo a raya tanto como se pueda, es ensayar una descripción negativa de los sueños; es decir, una en la que, en lugar de intentar determinarlos por lo que son, determinación en la cual podría filtrarse subrepticiamente el modo de ser de la vigilia, intentemos determinarlos por lo que no son, por las diferencias que muestran con el mundo de la vigilia. En otras palabras, se trata de ensayar una descripción que los preserve en su diferencia, en su "otredad". Tal vez, al estudiar más tarde cómo es que asimos los sueños, podamos ver que introducimos en ellos una serie de determinaciones positivas (Los sueños son así y así), que la descripción negativa rechazaba (Los sueños no pueden ser así y así).

\subsection{Caracterización negativa de los sueños}

Veamos sólo algunos rasgos notables de los sueños, en los cuales se deja ver su diferencia con el mundo de la vigilia.

1) Las cosas que en sueños se aparecen como cosas físicas no responden a una legalidad física reconocible: no se verifica en ellas el principio de causalidad, ni en general, una estabilidad predecible en el "comportamiento de lo físico". Puedo ver en sueños que una cosa desaparece sin más (se esfuma) o que aparece ex nihilo. Puede algo convertirse en un instante en otra cosa completamente distinta, etc.

2) Los individuos que en sueños son identificados como individuos de una especie biológica determinada no se avienen necesariamente ni al comportamiento-deespecie, ni a sus caracteristicas físicas, posibilidades o limites específicos. Los animales pueden hacer cosas que son propias del ser humano (hablar, deliberar, lo que fuere) y los humanos, cosas propias de algunos animales (volar, vivir bajo el agua, etc.). Además, en sueños no hay la menor constricción para que una mujer humana dé a luz un murciélago. No se verifica, necesariamente, algo así como un "núcleo duro" que determine la identidad de las especies.

3) También las identidades personales tienen un "grado de libertad" mucho mayor (no están constreñidas por un "núcleo duro" -y si bien esto es ontológicamente cuestionable, el ejemplo que sigue ilustra suficientemente el punto). Puedo ver en sueños a alguien que tiene el aspecto físico de $A$, cuya profesión es la que reconozco, una vez despierto, como la de $\mathrm{B}$, pero al que yo identificaba, mientras soñaba, como C ("sabía" que era $\mathrm{C}$ ).

4) "Saber" algo, en sueños, o experimentar el sentimiento de certeza no requiere de una justificación ni de una evidencia más allá del mero sentir que se sabe (luego desarrollaré más este punto). Yo puedo, en sueños, estar cierto de que hay un león del otro lado de la pared, aun cuando el sueño no haya puesto ni el león "a la vista", ni un cartel que diga, "Cuidado: león del otro lado de la pared", ni haya aparecido antes el testimonio de alguien advirtiendo sobre el león.

5) Las emociones que se experimentan en sueños pueden haber sido motivadas por cualquier objeto (en sentido amplísimo), sin que haya una correlación más o menos estable entre la emoción y el objeto que la motiva. Se puede soñar con la muerte de alguien muy querido y permanecer indiferente a ello, entristecerse o entrar en pánico por cosas que en vigilia juzgaríamos nimias, etcétera. Esto sugiere que no hay una estabilidad de los valores: lo valioso, lo no valioso, qué sea un bien y qué no, no se muestran como formando parte de una jerarquía más o menos estable.

La lista podría seguir $-y$, por lo demás, este breve inventario ha sido expuesto de manera más bien tosca-. Pero es suficiente para hacer las indicaciones que interesan aquí. 
Lo primero que se ve es el hecho de que todas estas características, y otras varias que podrian mencionarse, señalan no-regularidades de diverso orden, que sí son regularidades propias del mundo de la vigilia ${ }^{33}$. 0 para decirlo afirmativamente, los sueños gozan de un ámbito de lo posible que rebasa, en diversos órdenes (físico, ontológico, "epistemológico", axiológico, práctico) ${ }^{34}$, los límites propios del mundo de la vigilia. No es que en todo sueño se realicen efectivamente algunas de estas posibilidades (imposibilidades en vigilia), sino que a todo sueño le es propio este ámbito de lo posible, ya sea que lo realice efectivamente en mayor o en menor medida -o aun en una especie de grado cero, en el que lo soñado no muestra nada que indique su posibilidad de rebasar el ámbito de lo posible de la vigilia.

Ahora bien, en la medida en que las constricciones o límites se relajan, y se incrementa el ámbito de lo posible, disminuye a la vez la posible estabilidad de los fenómenos (de lo que se aparece) y se incrementa el ámbito de lo esperable. Es decir: si estando despierto veo un oso, éste se me aparecerá como oso mientras lo esté mirando; y si una bola de billar va a chocar con otra, no sólo no veré que la bola de billar se transforma en paloma y se echa a volar (y me dice: "Soy una bola, me voy bolando", y me dedica un guiño), sino que la trayectoria que siga la bola que ha sido impactada se me aparecerá como una trayectoria más o menos esperable. $Y$ así con los diversos aspectos señalados antes, y otros que podrían agregarse. Pero en sueños el oso puede hablar, fumar un puro, transformarse de un momento a otro en un gusano, desaparecer... Los "fenómenos" en los sueños son, potencialmente, mucho más inestables, y por eso el ámbito de lo esperable se amplía de manera extraordinaria. Con todo, los sueños gozan de un mínimo de "estabilidad fenoménica", pues, de otro modo, resultarían totalmente ininteligibles para el yo despierto. ¿En donde radica la mínima inteligibilidad de los sueños?

Para comenzar, en sueños no se cancela la síntesis trascendental del tiempo ${ }^{35}$. Se cancela, sí, el modo de ser del tiempo lleno de la vigilia, pero no la forma en que opera el flujo. Evidencia de esto es que un objeto que se aparece en sueños, pongamos una silla, puede haber aparecido como de la nada, pero durante el tiempo en que se muestra como silla, lo hace como un objeto que es uno y el mismo, y que además es percibido como durando en el tiempo. Y para que esto se dé, es necesario que la conciencia opere sobre la base de la sintesis trascendental del tiempo. Pero, de otro lado, al no regir en sueños la legalidad física que rige en vigilia, de un instante a otro la silla puede desaparecer o transformarse en cualquier otra cosa, o adquirir cualidades de cualquier tipo. Y así es que lo protencionado, la mención vacía de una silla que todavia-no-es, adherido a la impresión de la silla soñada ahora, bien puede no llegar a ser. En sueños, la protención no constituye un fundamento para la anticipación, como en vigilia. Cada ahora del sueño abre un abanico extraordinariamente vasto de posibles direcciones a seguir.

Generalmente, el sueño muestra lapsos de sostenida continuidad, pero en ocasiones se dan (o creemos recordar que se dan) cortes abruptos. Esto es posible porque el sueño no está constreñido casi por ninguna otra necesidad que la de la sintesis trascendental del tiempo (y seguramente, las sintesis pasivas de asociación, con todo lo que de suyo entrañan), en que se constituye la unidad e identidad de los objetos temporales. Pero los objetos soñados siempre pueden, teóricamente, limitarse al mínimo lapso requerido para mostrarse como objetos que son, cada cual, uno y el mismo, y mudar luego por completo o desaparecer, puesto que lo que adviene siempre puede ser la cancelación o la transformación abrupta de lo recién-sido.

Al no haber casi constricciones, al tener, en consecuencia, un ámbito de lo esperable tan extraordinariamente amplio, no hay en sueños algo así como una estabilidad en la que se puedan fundar ni anticipaciones ni expectativas de futuro de ningún tipo: EL HORIZONTE DE FUTURO DE LA CONCIENCIA SOÑANTE SE LIMITA A LA PROTENCIÓN, A LA INTENCIÓN DIRIGIDA HACIA LO QUE TOdAVIA No-ES. Puesto que el sueño tiene la permanente posibilidad de cambiar por completo el "escenario" (y aquí diriamos, quizá con cierta latitud, que termina una parte del sueño y comienza otra), puesto que no existe, en sueños, la posibilidad de que lo que se muestra en el ahora "anticipe" lo que se mostrará a continuación, no puede decirse que sea una determinación necesaria o esencial de la conciencia soñante el apuntar hacia un futuro mediato y dirigirse hacia alli. El soñante carece de futuro mediato; por lo tanto, carece de algo así como apuntar a un objetivo. Esto también se verifica en el hecho de que cuando recordamos los sueños, no suele ser reconocible un desenlace en sentido propio, algo que por sí mismo se deja ver como final cerrado, consumación de algo a lo que se llega, o conclusión, sino que el fin del sueño coincide simplemente con su interrupción. $Y$ en la interrupción no se advierte un motivo que la justifique como tal: el sueño bien podría 
haber continuado (se trata, a lo mucho, de algo así como un final abierto).

Siendo que en sueños el horizonte de futuro no puede extenderse más allá de la protención, la conciencia soñante está, en todo momento, casi puramente absorbida en su ahora (entendido éste, siempre en el sentido de un presente espacioso que comprende, a la vez, las intenciones de futuro y pasado inmediatos). Cada "imagen" subsiguiente es la realización de una de las vastísimas posibilidades que podrian suceder al ahora. En esta realización, se ve que suelen mantenerse algunas líneas de continuidad entre lo que se muestra en el ahora y en lo que acaba de mostrarse, pero también se ve que hay muchas otras discontinuidades, que son las que nos llevan a enumerar cosas como las de 1)-5).

En cuanto al pasado del sueño, para la conciencia soñante, no hay más pasado que lo ya soñado antes de cada ahora. Por otro lado, si el sueño muestra dos sujetos que son amigos, eso basta para que se acepte y se "sepa" sin más de la amistad entre los sujetos: son afectivamente comprendidos como amigos por la conciencia que sueña ${ }^{36}$, sin que sea necesaria una explicación histórica, un testimonio o cualquier otra evidencia que implique una alusión al "pasado del sueño". En sueños, comprendo afectivamente en cada momento dónde estoy, quiénes son ésos, qué relación tienen conmigo, etc. -si no lo "sé", esto es también parte de mi comprensión afectiva: comprendo que no lo sé-. "Sé", en sueños, que hay un león del otro lado de la pared, porque le temo, o porque le tengo compasión, o por el mero hecho de que "siento su presencia".

Siendo, pues, que el sueño no requiere de un pasado que explique el presente, y siendo que no hay mayor horizonte de futuro que lo que en cada instante va siendo protencionado (tal vez estoy exagerando y la extensión hacia el futuro es apenas mayor, pero sólo apenas), EL SUEÑO ES LA INCESANTE REALIZACIÓN DE UN HIC ET NUNC CASI ABSOLUTO. Lo que efectivamente suele darse es que el sueño discurra con una continuidad que nos resulta luego reconocible, y esto, porque así como el sueño toma su "materia prima" de las impresiones de la vigilia, también imita, o reproduce, a su modo, la continuidad decursiva entre apareceres sucesivos $^{37}$. Entre las muchísimas posibilidades, direcciones que en cada instante puede tomar el sueño, es más probable que siga aquella que imita la continuidad decursiva de la vigilia: pero es sólo más probable; no es imposible que en sueños una "escena" tome un rumbo completamente inesperado, discontinuado, etc. (si bien lo inesperado o discontinuado no lo son para el soñante, sino para los parámetros de vigilia). $Y$ esto es lo esencial.

Hecha esta caracterización negativa, veamos ahora el tipo de características que le atribuimos a los sueños, a fin de poder juzgar si estas atribuciones positivas son consistentes con lo anterior, o si, al contrario, se revelan completamente ajenas a los sueños mismos. Valdría aquí preguntar algo así como: ¿Que le atribuimos quiénes? Esto se irá viendo en la sección que sigue; provisionalmente, diré que se trata de algo así como de "atribuciones de término medio", es decir, atribuciones más o menos instituidas en la vida de término medio (en el sentido de Heidegger), en la cotidianeidad mediana.

\subsection{Inoculaciones de la vigilia: el problema de las atribuciones positivas}

Todo lo que acabamos de decir acerca de lo estrecha, inmediata que es la conciencia de futuro durante el soñar, de lo breve que es el pasado en el sueño (se limita a lo ya soñado), y en suma, de un hic et nunc hiperbólico, no se hace manifiesto cuando recordamos nuestros sueños, puesto que no "percibimos" al sueño en su estar soñándose, sino que lo aprehendemos, una vez despiertos, como un todo ya constituido.

Hemos dicho antes que, al aprehender un sueño -pongamos que recién despiertos, con el yo vuelto hacia lo recién percibido-, lo marcamos como "sueño", cuando originariamente el ser-sueño no se había mostrado durante el soñar (salvo en los casos del tipo "Esto es un sueño"). Esta marca es inevitable y se funda en la posibilidad, exclusiva de la vigilia, de percibir la diferencia entre el modo de ser de la vigilia y el modo de ser de lo soñado: el mundo de vigilia es percibido como el Mismo; lo soñado, como lo Otro. Pero que lo soñado sea percibido como Otro reside, precisamente, en las diferencias que éste guarda con el mundo de la vigilia, de las cuales 1)-5) son sólo algunas; ellas, y todas las demás que pudieran describirse, se fundan en el carácter autónomo del soñar con respecto a la vigilia (en el sentido antes indicado); pues es ésta su autonomía la que libera a lo soñado de verse constreñido por las legalidades y necesidades de la vigilia, y le confiere un ámbito de lo 
posible notablemente más amplio. De modo que a la marca de "sueño", que el yo despierto necesariamente hace de lo recién percibido, pueden agregarse otras atribuciones que surgen de advertir más concretamente las diferencias entre lo Mismo y lo Otro. Todo el asunto estriba en si esas diferencias son atribuidas como diferencias originarias 0 no. Lo primero conduce a una caracterización negativa, como la ensayada antes; lo segundo, a hacer atribuciones positivas (asertivas) acerca de cómo son los sueños, y a partir de esto, a una serie de confusiones y sinsentidos.

Una caracterización negativa parte de las diferencias que hay entre el modo de ser del soñar y el modo de ser de la vigilia. Es inevitable que esta diferenciación se haga en vigilia, pero es justo por esto por lo que se intenta describir a lo Otro en cuanto Otro; esto es, a los sueños en cuanto sueños que se ofrecen ORIGINARIAMENTE a una conciencia Otra: la conciencia que sueña -y a la que le es esencial la cancelación del yo de vigilia. El yo de vigilia, que es el que reflexiona teóricamente, parte aquí del reconocimiento de esta asimetrí; todas las afirmaciones que pueda hacer tienen a la base este primer reconocimiento, negativamente determinado.

Una caracterización positiva procede de manera inversa. Al hacer afirmaciones acerca de los sueños y el soñar, no se parte del reconocimiento de una asimetría originaria; no se habla de los sueños en su originario ofrecerse a una conciencia soñante, y por lo tanto, se pasa por alto el originario no ofrecerse de los sueños a la conciencia de vigilia, cancelada mientras se sueña (la pura receptividad que atestigua la dación de lo soñado es una pre-conciencia de vigilia, que no tiene todavía un carácter propio ${ }^{38}$ ). En otros términos: no se caracteriza a lo Otro en cuanto Otro, sino que las diferencias que se señalan son diferencias no originarias, que quedan absorbidas dentro del ámbito de lo Mismo.

Negativamente puede caracterizarse a lo que se aparece en sueños como algo que no está sujeto a diversos órdenes de regularidad. Positivamente, todo lo que pueda decirse de los sueños es por comparación con la vigilia, pero sin hacer patente la asimetría que está a la base de esta comparación. Al hacer esto, no se dice nada sobre los sueños mismos.

Un ejemplo. Comparamos los sueños con el mundo de vigilia y decimos cosas como: "Muchos sueños son extraños, confusos, incoherentes, enigmáticos, oscuros, mágicos, extravagantes, absurdos, maravillosos, etcétera, etcétera". Pero los sueños no son ninguna de estas cosas. Porque no pueden serlo. Para poder afirmar que hay sueños absurdos, incoherentes, etc., y que es parte de las posibilidades esenciales de los sueños el ser absurdos, tendríamos que afirmarlo sobre la evidencia de que el sueño se muestra absurdo para la conciencia que sueña; que el sueño se muestra incoherente para la conciencia que sueña, etc. $Y$ el caso es que el sentido de lo absurdo puede mostrarse en sueños asociado a objetos soñados (sueño con una manzana y la experimento, en sueños, como absurda), pero no como un carácter del sueño mismo, por el mero hecho de que la conciencia soñante no es consciente de que el mundo en que se halla envuelta es un cuasi-mundo: un sueño. El yo del sueño no vive el sueño como algo esencialmente absurdo, extravagante, mágico, coherente o incoherente, confuso o claro. (El soñante puede experimentar un sentimiento del tipo: Ah, todo es absurdo, sentimiento que muchos solemos experimentar también en vigilia. Pero de nuevo: el todo que mienta el soñante es el cuasi-mundo entero del sueño, del cual él, sin embargo, no es consciente como cuasi-mundo, sino como mundo. Y si el soñante experimentara algo así como: Ah, todo es absurdo porque estoy soñando y en los sueños las cosas pueden ser absurdas, estariamos en una versión del caso "Esto es un sueño".)

Por otro lado: la conciencia soñante va soñando cada ahora; las direcciones que el sueño puede tomar en cada momento son, teóricamente, casi ilimitadas: puede lo mismo mantener ligas fuertemente reconocibles entre ahoras sucesivos, que cancelarlo todo. En estas condiciones, coherencia o incoherencia, confusión o claridad, extravagancia, maravilla, absurdo, no son siquiera posibilidades del sueño. Porque todos estos calificativos suponen límites para poder ser aplicados, límites que valen para la vigilia, pero que no son propio de los sueños.

Contra este segundo argumento puede objetarse que podría haber límites más estrechos, aun para los sueños, como sugiere el hecho de que éstos muestren a menudo algo así como una "narración" reconocible -estos límites podrian ser, por ejemplo, constricciones impuestas por sintesis asociativas. Pero aun cuando fueran límites más estrechos que los que he sugerido, serían de todos modos muchísimo más amplios, laxos, que los de la vigilia; con

ARBOR

CLXXXV 736 marzo-abril [2009] 403-426 ISSN: 0210-1963

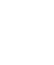


lo cual, hablar de coherencia, incoherencia y cosas del estilo sería, también en ese caso, formular atribuciones que tendrian sentido para los límites de la vigilia, pero no para los límites de los sueños.

Así, pues, todas éstas son determinaciones (calificaciones) que la vigilia atribuye a los sueños, creyendo decir algo sobre ellos, cuando en realidad dice algo sobre ella misma, refiriéndose, sin embargo, a los sueños. Decir que los sueños son absurdos, incoherentes o cosas de este tipo, no es decir algo verdadero o falso acerca de los sueños, porque no es decir algo acerca de los sueños mismos. Por lo tanto, es no decir algo con sentido: un sinsentido.

Un tipo de sinsentido eminente se da cuando se atribuye a los sueños (o a una cierta clase de sueños) un sentido oculto, susceptible de ser descifrado a través de una interpretación. Este caso es quizá más difícil, pero indicaré brevemente en dónde me parece que radica el sinsentido.

Hay que notar, en primer lugar, que este "verdadero significado", por permanecer oculto (cifrado, enmascarado), no se ofreció en el soñar mismo, para el soñar mismo. De acuerdo con lo dicho antes, esto es ya una extralimitación que rebasa el ámbito de dación del sueño, que es el único que puede considerarse originario en sentido estricto. Porque si se dice que el sentido sí se ofreció, pero cifrado, enmascarado, o como fuere, todo lo que se está diciendo es que no se ofreció a la conciencia soñante, sino que se ofrece a ser interpretado por la vigilia. Sólo con esto se adivina ya una circularidad, a la que no puede escapar ninguna propuesta de interpretación de los sueños. Pero hay que conceder a este problema alguna atención, dada su popularidad y la posibilidad de que muestre fundamentos que aquí hayan sido descuidados.

¿Qué tiene que tener un sueño para ser susceptible de una interpretación, en el sentido de la onirocrítica antigua, de Artemidoro o de Freud? En primer lugar, debe tener un "significado" distinto del sentido que se muestra. Surge así la distinción entre un sentido literal y aparente (que aparece, pero también, que es "sólo apariencia"), y uno no-literal y oculto, que es el "verdadero sentido" del sueño; el primero está cifrado; el segundo se alcanza descifrando el primero. Si lo que permite dar el salto del primero al segundo es ver en lo primero, no lo que literalmente se muestra, sino una alegoría o un simbolismo, entonces el sentido oculto es un sentido alegórico o simbólico ${ }^{39}$. Pero si el sentido literal se oculta bajo máscaras más complejas, entonces, para alcanzar el sentido oculto será preciso conocer cuáles son esas máscaras, cómo es que han sido puestas, y recorrer el camino inverso para quitarlas. $\mathrm{Si}$, pongamos, reconozco que el sujeto que se aparecía en sueños tenía el aspecto de $A$, la profesión de $B$, pero yo sabía, al soñarlo, que era $C$, entonces puedo ver que hay una "condensación" de tres personas de mi mundo de vigilia que por alguna razón o motivo se funden en un solo sujeto. Para conocer la razón, tengo que "descondensar" a los tres e intentar ver qué puede ser aquello que ha determinado que se vieran condensados en el sueño.

Tomemos el ejemplo de la condensación, que es, según Freud, uno de los cuatro factores que intervienen en la "elaboración del sueño" (una de las maneras por medio de las cuales el sentido latente, que es el verdadero sentido, se disfraza y adquiere la apariencia del sueño tal como se muestra $=$ sentido manifiesto $)^{40}$. Otra vez hay que decir lo mismo aquí: yo puedo advertir, una vez despierto, no sólo que en lo que el sueño me mostraba hay un $A$ y un $B$ y un $C$ (si atribuyo esto al sueño mismo, estoy ya haciendo una atribución positiva), sino también que, mientras soñaba, No había la conciencia de un $A$ y un B y un $C$, ni de una condensación, ni de nada del estilo.

Un ejemplo quizá más claro. Yo no sueño algo así como que alguien viene a visitarme a mi vieja casa, en Montevideo, y, luego de un "corte" (o peor, iuna elipsis!), esa persona y yo caminamos por un barrio que se parece a Coyoacán, en la Ciudad de México, pero en cuya plaza, en lugar del arco que efectivamente se alza en Coyoacán, está el Arco del Triunfo. ¡No! Yo sueño que estoy en mi casa (en una casa que comprendo afectivamente como mi hogar) y que la persona que me visita y yo decidimos salir, y caminamos por un barrio colonial -que tal vez se llame en sueños Coyoacán, o tal vez no, tanto da-, donde pasamos por debajo de un arco así y así. La "geografía" que muestra el sueño, su espacialidad, es consistente consigo misma, y no reconoce nada parecido a haber pasado de una casa ubicada en una ciudad, a un barrio ubicado en otra, donde había un arco de una tercera ciudad. Sencillamente yo no sueño nada de esto.

La condensación, por sólo mencionar un criterio de "onirocrítica", no es algo que se muestre originariamente, no 
pertenece al sueño ni al soñar. De modo semejante, la razón que se busca para explicar la condensación, lo mismo que el afán explicativo, responden a una teleología que es característicamente del mundo de la vigilia -y que podríamos designar, en una línea husserliana, una teleología de la razón ${ }^{41}$. Presuponer que el sueño ha sido "elaborado" siguiendo los parámetros de una teleología de la razón es algo que el sueño mismo no muestra y no puede mostrar jamás; es, de nuevo, una atribución positiva que la vigilia hace del soñar y del sueño.

El caso de la condensación y la razón que ella anima a buscar (¿Por qué A, B y C aparecen así condensados?) no dice absolutamente nada sobre el sueño mismo, pero dice mucho acerca de la interpretación de los sueños; fundamentalmente, que se trata de una interpretación de la vigilia, por parte de la vigilia, con la mediación de algo a lo que se llama sueño, que sin embargo, no es jamás el sueño mismo (he aquí el sinsentido). Esta circularidad aqueja a cualquier aparato hermenéutico destinado a interpretar los sueños, y se funda en una petición de principio que envuelve tres conceptos: teleología, motivo y criterio; funciona, en pocas palabras, así. Quien interpreta los sueños es porque cree que todo sueño tiene un sentido que puede ser determinado; basa su creencia en una premisa teleológica, según la cual todo lo que se aparece en sueños, cada detalle, el modo como se muestra, si lo hace antes o después, si coexiste en su aparecer con otros, en fin, todo tiene su razón de ser (su "para qué"), su motivo, o si se prefiere, su función: nada ha sido puesto arbitrariamente en el sueño. Para justificar adecuadamente esta premisa teleológica habría que poder mostrar una teleología general, válida para todo sueño posible. Pero esto sólo podría ser una atribución positiva, es decir una determinación teleológica ajena a los sueños mismos, y propia de la vigilia. El modo de "escapar" a esto es hacer ver que, efectivamente, en cada detalle de cada sueño que se proponga, se podrá siempre reconocer que ese detalle, alli, obedece a una razón o motivo. Pero puesto que hay infinitos detalles de infinitos sueños posibles, será necesario establecer criterios generales que permitan determinar los motivos particulares de cualquier sueño posible. $Y$ aquí está el problema, porque todo criterio es, necesariamente, una atribución positiva (como se vio, por ejemplo, con el caso de la condensación de A, B y C: la condensación era una atribución positiva, no algo que originariamente mostrara el sueño).
Más aún, la adopción de cualquier criterio presupone necesariamente que hay algún motivo dado, así como el tipo de motivo dado. Así, el criterio de condensación entraña la pregunta acerca de por qué (cuál es el motivo por el cual) $A, B$ y $C$ se han visto reunidos, pero entraña, en general, la pregunta por la condensación. El criterio alegórico o simbólico, preguntará cuál es el motivo de que haya aparecido un pozo de agua en un sueño (qué significa alegórica o simbólicamente el pozo) ${ }^{42}$, pero en general, la pregunta por el símbolo o la alegoría; y lo mismo con cualquier criterio.

UNA HERMENÉUTICA DE LOS SUEÑOS DICE OFRECER CRITERIOS QUE PERMITEN VER LOS MOTIVOS DE TODO LO QUE APARECE EN SUEÑOS, Y CON ELLO, OUE HAY UNA CIERTA TELEOLOGÍA PROPIA DE LOS SUEÑOS (Y DE CADA SUEÑO PARTICUlar). Pero los criterios SON de Vigilia, PREguntan POR motivos de LA VIGILIA (MOTIVOS QUE, POR LO TANTO, SIEMPRE PUEDEN SER ENCONTRADOS) Y POR LO TANTO, NO HACEN SINO DESTACAR UNA TELEOLOGÍA ORIGINADA EN LA VIGILIA, A SABER: ENCONTRARLE UN SENTIDO OCULTO A LOS SUEÑOS; ÉSTA NUNCA PUEDE SER UNA TELEOLOGIA DE LOS SUEÑOS MISMOS.

Así, pues, tanto da si unos criterios parecen más dúctiles que otros, si parecen "verificarse" en mayor cantidad de casos, verse "confirmados" en mayor medida "por la experiencia": todo lo que esto quiere decir es algo parecido a que la experiencia se confirma a sí misma. En este sentido, Freud y Artemidoro están igualmente lejos del propósito que creen haber alcanzado. (Esto no significa que desde el punto de vista práctico la interpretación de lo sueños -o más bien, la interpretación de la vigilia, referida a los sueños-, sea estéril. Que un paciente comprenda mejor su vida o tenga un insight, o varios, a partir de lo que su psicoanalista le dice "sobre sus sueños", habla de la eficacia práctica del método, o de la capacidad persuasiva del psicoanalista, o de algo del estilo; pero no dice nada a favor de la teoría de los sueños que le subyace.)

Para apoyar la tesis contra la interpretación de los sueños, podría agregarse todavía que, como hemos vista ya, cada sueño es un ir haciéndose que carece de un futuro mediato, de un final al que se apunta a modo de finalidad o propósito (telos). Una hermenéutica de los sueños toma el sueño como un todo ya constituido y apela a algo así como "causas finales" (el fin de cada sueño es revelar un mensaje profundo), cuando lo que se ve es que parecería haber más bien un incesante ir realizándose, efectuándose, sin una meta pre-establecida. De todos modos, lo que he dicho es incompleto, pues debería aun describirse cómo 
es que se va dando esta continua efectuación. El único camino que me parece plausible, según he sugerido ya, es explorar las síntesis pasivas de asociación entre contenidos de conciencia.

Así, pues, ciertas calificaciones que se hacen sobre los sueños, lo mismo que las interpretaciones que persiguen desentrañar, bajo presupuestos teleológicos, sentidos ocultos, tenidos por más originarios, nada dicen sobre los sueños y no pasan de ser sinsentidos.

Éste es un riesgo que se corre al hacer cualquier atribución positiva, ya sobre los sueños en general, ya sobre un sueño en particular. Con esto no quiero decir que toda atribución positiva esté condenada a ser un sinsentido, pero sí que muchas de las que solemos hacer (atribuciones de término medio) entran dentro de este dominio.

Es por esto por lo que a una fenomenología positiva de los sueños debe, necesariamente, precederle una fenomenología negativa; el papel de esta última es vigilar, en todo momento, que los asertos de la primera digan algo sobre los sueños mismos y no rebasen los límites de lo que se muestra en lo soñado en cuanto tal -límites que determinan el ámbito de lo decible acerca de los sueños. La división es, por supuesto, analítica, un horizonte normativo, por así decir, pues es inevitable que las atribuciones negativas colinden con las positivas, y las páginas anteriores son prueba de ello; en efecto, hubo, no sólo descripciones negativas, sino también positivas, como cuando se trazó un bosquejo sobre la temporalidad del soñar. El paso inmediatamente siguiente a aquel bosquejo, además de refinarlo, sería, a mi modo de ver, describir genéticamente cómo se desenvuelven en sueños las demás síntesis pasivas (la candidata que se insinúa primera parece ser la síntesis de asociación entre contenidos homogéneos).

\section{Conclusiones: Fenomenología del UMBRAL Y FENOMENOLOGÍA NEGATIVA}

La segunda parte tenía, entre otros, el propósito de intentar evaluar el resultado alcanzado hacia el final de la primera (5.2). Parecía, en un principio, que se trataba de un resultado algo trivial, una recomendación metodológica para obtener la mejor muestra empírica; como si, por así decir, todo lo que le había precedido no hubiera sido sino un manual para construir el mejor atrapasueños posible. Pero en realidad, el resultado ya revestía algún interés. En primer lugar, la descripción del umbral entre el soñar y la vigilia permitía determinar si nuestros recuerdos de sueños podian aspirar a ser una evidencia adecuada para un estudio de los sueños o no; hasta donde he visto, no es un trabajo crítico que se haya acometido antes, y por eso, los estudios fenomenológicos sobre esta materia no han estado, a mi parecer, cabalmente fundados. Como consecuencia, se le abria la puerta a algunas formas de escepticismo (no exactamente el de tipo cartesiano) surgidas en el seno de la filosofía analítica. Si las descripciones relativas al tránsito entre el soñar y la vigilia son correctas, entonces hay un conjunto de condiciones bajo las cuales lo que recordamos de los sueños constituye una evidencia fiable. Esto no había sido enfatizado, pero era ya una primera consecuencia de aquel resultado.

Sin embargo, ese conjunto de condiciones parecia problemático. No era claro qué posibilidades reales abría para una fenomenología de los sueños y en qué sentido no se limitaba a ser un manual de atrapasueños. Lo que entonces quedaba asentado era que, de proceder de cierta manera, la "pérdida" y aun la "adulteración" de lo soñado iba a ser tan minima como fuera posible. Esto no parecía señalar sino un procedimiento con vistas a perder la menor "cantidad" posible del sueño recién soñado; y no se veía, de momento, qué era aquello de la adulteración.

Fue necesario contrastar una caracterización negativa de los sueños, con una positiva, para poder evaluar todas aquellas atribuciones que creemos hacer acerca de los sueños, y que sin embargo no dicen de ellos nada. Entre estas atribuciones sin sentido se cuentan aquellas que se hacen en términos de coherencia-incoherencia, absurdidad-inteligibilidad, oscuridad-claridad, y otros calificativos del estilo; también, las atribuciones relativas a sentidos ocultos, presuntamente más originarios, que reclaman ser descifrados a través de algún tipo de interpretación u onirocritica. Con esto se indicaba el riesgo que se corre al atribuirle positivamente a los sueños ciertas características o determinaciones. Y éste es, precisamente, el riesgo que los resultados de la primera parte aseguraban evitar, 0 al menos, acotar en la mayor medida posible (lo que anunciábamos como posibles "adulteraciones" se reveló luego en términos de sinsentido). 
¿Pero en qué estriba que aquellas condiciones que se describieron como las más apropiadas para aprehender los sueños garanticen evitar atribuciones sin sentido? Esto es lo que no se ha dicho todavía, el lazo que falta entre la primera y la segunda parte.

La garantía estriba en que esas condiciones, que conminan a un apego a la receptividad más pura posible, son la determinación de una "actitud" cuyo exacto correlato teórico es una fenomenología negativa de los sueños. $Y$ esto por lo siguiente. Para describir negativamente, como se ha hecho en 6 , es preciso no introducir en la descripción nada ajeno a los sueños mismos. Y para ello, es preciso ver pura y exclusivamente qué es lo que los sueños traen originariamente consigo; qué es lo que se ofrece en el soñar. Esto es imposible estando despiertos, pero el ver fenomenológico que más tiende a ello es, justamente, aquel que se apega a la receptividad más "diáfana"; diría, a contrapelo de la onirocrítica, que es aquel ver que más se apega a la literalidad del sueño, "a la cosa misma"43. Dejarle el ingreso, en ese momento, a niveles más altos de actividad, a actos de orden su- perior, uno de los cuales sería, desde luego, iniciar una "interpretación del sueño", es perder el sueño mismo, sustituyéndolo por otra cosa, y creyendo haberlo aprehendido en su originariedad.

Una fenomenología negativa de los sueños -que es, por lo que he dicho, condición indispensable para poder desarrollar una fenomenología positiva-, sólo puede fundarse en un ver receptivo, que procure estar tan "adentro" de lo sueños como sea posible, partiendo, en primerísimo lugar, por reconocer un "adentro" originario, distinto del afuera desde el que se mira. Se trata, en cierta medida, de una fenomenología que se ubica en el límite entre el adentro y el afuera, el soñar y la vigilia. Por eso, la caracterización negativa, esbozada en la segunda parte, no fue sino la continuación natural de la fenomenología del umbral, desarrollada en la primera.

Aquí no he hecho otra cosa que ensayar una fenomenología del umbral, con vistas a una fenomenología negativa de los sueños, señalando, de paso, los resultados laterales que la descripción iba dejando ver.

\section{NOTAS}

Recibido: 25 de diciembre de 2007

Aceptado: 15 de enero de 2008
1 El, así llamado, "soñar despierto" no puede ser tenido por un soñar en sentido propio; la expresión no sería algo así como un oxímoron que sugiriera la conciliación de lo que parece excluyente. Más bien, "soñar", en este caso, recibe esa designación, ya porque se trata de un modo de imaginar que hace olvidar, a quien imagina, de estar imaginando -y el soñar implica, como se verá, no tener conciencia de que se está soñando-, ya porque "soñar" suele utilizarse en el sentido de presentificar aquello que se anhela. "Sueño con estar echado bajo una palmera, tomando agua de coco y mirando el mar", digo e imagino (presentifico) la playa tropical y el coco y el mar, estando, sin embargo, en un departamento de un edificio de una ciudad gigantesca, ubicada a cinco horas (imínimo!) del mar. Traigo a presencia aquello que deseo.

2 Baso esta afirmación, no sólo en algunas lecturas de Husserl y otros fenomenólogos, sino en una conferencia de Julia V. Iribarne, ofrecida en 2001 y titulada "Aportaciones para una fenomenología de los sueños", en la que la autora pasa revista al "estado de cosas presente en cuanto a los estudios de fenomenología de los sueños". Se comentan alli las posiciones de Husserl, Jean Hering, Theodor Conrad, Jean-Paul Sartre, Eugen Fink y Hans R. Sepp, además de la que asume la propia Iribarne. Con esto no pretendo afirmar, categóricamente, que no se ha abordado fenomenológicamente jamás una crítica del acceso a nuestros sueños, sino que, hasta donde yo he conse- 
guido ver, sólo hay alguna alusión menor. Es el caso, por ejemplo, de Alfred Schutz y Thomas Luckmann, quienes, en su breve descripción de "El mundo onírico", observan: "No podemos aprehender la esfera de los sueños sino mediante la 'comunicación indirecta', para usar una expresión de Kierkegaard. Esto significa, sin embargo, que los procesos subjetivos de los sueños sólo pueden ser comunicados, por así decir, mediante un contraste 'negativo', o sea, por su diferencia con respecto a las estructuras de sentido de las vivencias de la vida cotidiana"; en Las estructuras del mundo de la vida, p. 52.

3 Véase, Meditaciones metafísicas, Meditación Primera. Aunque, estrictamente, el problema es inaugurado por Platón, cuando, por boca de Sócrates, le pregunta a Teeteto: "¿qué prueba (tekmérion) se podria presentar al que nos preguntara si ahora, en este preciso momento, estamos dormidos y soñando todo lo que estamos pensando, o si no sólo estamos despiertos, sino que además estamos dialogando unos con otros en estado de vigilia?", Teeteto, $158^{\text {b-c }}$; el paréntesis es del traductor.

4 Véase, por ejemplo, el artículo de Norman Malcolm, "Dreaming and Skepticism", donde se acaba negando que al relatar un sueño estemos recordando algo que efectivamente nos haya pasado; en consecuencia, los sueños no serían experiencias. Daniel C. Dennett critica a Malcolm, pero también propone, aunque con una estrategia distinta, que lo que llamamos sueños podrían no ser experiencias; véase su artículo "Are Dreams Experiences?".

5 Dejo de lado, para no complicar innecesariamente el análisis, casos como recuerdos de alucinaciones 0 de vivencias vividas en estados de conciencia alterados por sustancias psicotrópicas.

6 En ocasiones, uno sabe que sueña, como si en medio del sueño se dijera: "Esto es un sueño". Más adelante comentaré estos casos.

7 Cfr. Experiencia y juicio, § 17.

8 La receptividad, dicho esto un poco apretada y toscamente, es el puente entre la pasividad, en la que el yo no se orienta activamente en la constitución de sentido, y la actividad aprehensiva del yo. En la receptividad ya hay una captación de lo que le es pre-dado (la pasividad es la esfera de las pre-daciones), pero todavía no hay un dirigirse aprehensivo hacia lo captado. Con todo, la noción de pasividad admite otras acepciones que la que se ha ofrecido aqui. Véase la introducción de Anthony J. Steinbock a su traducción inglesa, Analyses concerning Passive and Active Synthesis (en adelante, ACPAS), que compendia las siguientes obras de Husserl: Formale und trazendentale Logik, (Hua XVII), Analyses zur passiven Synthesis (Hua XI), Aktive Synthesen (Hua XXXI) y Zur Phänomenologie der Intersubjektivität (Hua XIV); el autor distingue alli cinco acepciones distintas de pasividad.

9 Recuérdese que la receptividad es ya actividad del yo, si bien en su nivel infimo. Es cierto que mientras dormimos hay todavía un mínimo umbral de algo que estaríamos tentados de llamar receptividad; en efecto, un sonido estrepitoso, la pronunciación de nuestro nombre o algún otro estímulo puede despertarnos. Pero que haya este reducto, casi de alerta, indica tan sólo una disposición a responder a estímulos, no algo así como una permanente receptividad del entorno en cuanto mundo circundante.
10 "Cuasi", siguiendo a Husserl, porque las determinaciones espacio-temporales con que se presenta lo soñado no están integradas, propiamente, en la situación espacio-temporal del tiempo y el espacio absolutos (del tiempo y el espacio del mundo uno de la vigilia). Baste esta indicación por ahora. En 5.1, el asunto quedará mejor explicado.

11 Por otro lado, parece consistente que el despertar de la conciencia de vigilia comience por su nivel ínfimo de actividad y vaya ganando niveles superiores hasta alcanzar su plenitud.

12 Los Seminarios de Zollikon, editados por el médico y psicoterapeuta suizo Medard Boss, compilan las conversaciones y la correspondencia que éste mantuvo con Heidegger. El 2 de marzo de 1972 hablaron sobre los sueños. Heidegger observó: "Uno no puede decir, si se despierta, que entonces se encuentra en el mismo mundo; sino al revés: el despertarse consiste precisamente en que el mundo hace frente a uno como el mismo al que uno está acostumbrado estando despierto", p. 307 de la traducción castellana.

13 Husserl observa algo muy semejante, al decir: "En sueños, el Ego soñante se pierde en el sueño; se transforma en el Ego en el sueño, en el cuasi-sujeto de una cuasi-experiencia", Phantasy, Image Consciousness, and Memory (1898-1925), Texto n. 19 (1922-1923), p. 660; la traducción es mía; los subrayados, de Husserl. En la ya citada conferencia de Julia Iribarne, se refiere una discusión interesante entre Husserl y Eugen Fink; el primero, consistentemente con la cita anterior, dice que en sueños se da una "pérdida del mundo" ("el Ego soñante se pierde en el sueño"); el último observa que más bien se da 
un modo peculiar de tener mundo, que es el modo de la inmersión (Versukenheit).

14 Con esto no quiero decir, por supuesto, que ningún estímulo de la vigilia pueda ser percibido por el soñante; de ser así, los despertadores, los ruidos estrepitosos, las personas encargadas de despertarlo a uno, no lo despertarían jamás, y todo el despertar quedaría confiado a una tendencia surgida "desde dentro". Se conserva, naturalmente, un umbral de "alerta" con respecto a la vigilia. Pero este umbral no es suficiente para que el yo que sueña tenga conciencia de la vigilia qua vigilia, del mundo de la vigilia.

15 "Negativa" en el sentido de A. Schutz y T. Luckmann (véase nota 2): que el soñar se determina aquí como la no-vigilia, antes que por una determinación positiva.

16 Una evidencia indirecta y débil, a favor de esto, son aquellos casos en que presenciamos a otro que habla en sueños, o muestra un cierto tipo de actividad observable (el caso extremo sería el sonambulismo). Si el durmiente habla o, en fin, responde a ciertos estímulos que, como podemos atestiguar, no provienen del entorno (del entorno que el durmiente percibiría de estar en vigilia), entonces sólo podemos suponer que esos estímulos se presentan a su conciencia en el modo en que ésta se encuentra (que notoriamente es no-vigilia). Pero estos "estímulos" no pueden ser más que lo que solemos llamar sueños, de modo que tenemos que concluir que el durmiente está soñando al hablar o hacer ciertas cosas. Por otro lado, una vez despiertos, quienes así se comportaron durante el reposo no suelen recordar nada: ni que hablaron, ni un sueño que pue- da explicar su haber hablado. Pero ésta no es una evidencia firme, sino suplementaria. El precio que se paga por apelar a estos casos es toparse con objeciones que, en el fondo, sólo han podido surgir por haber abandonado la perspectiva fenomenológica de primera persona. Una objeción, sería, por ejemplo: ¿Cómo puedes asegurar que los comportamientos del durmiente, tales como hablar u otros, responden a ciertos sentidos de que el durmiente es consciente, a su modo, y no que son respuestas fisiológicas de algún tipo, cierta clase peculiar de estertores o lo que fuere? Cualquier respuesta que se pudiera dar a esta objeción no sería tampoco una respuesta fundamental. Habría que apelar a mediciones de los movimientos oculares rápidos (MOR), a registros de la actividad cerebral y a otros recursos de las ciencias positivas, pero ninguno de ellos podría fundamentar lo que aquí se desea fundamentar, a saber, una descripción esencial de dos modos de ser de la conciencia.

17 Un razonamiento análogo muestra por qué el escepticismo del argumento cartesiano del sueño resulta, a fin de cuentas, irrelevante. Efectivamente, yo podría estar soñando y no tengo manera de saberlo. Pero es justo porque no tengo manera de saberlo, de hacer una distinción "externa" entre el nivel en el que vivo mi vida y aquel otro nivel donde yo (u otro) la estaría soñando, que este mi nivel resulta inmune a ser relativizado o degradado ontológicamente. El tipo de distinciones que puedo hacer entre el soñar y la vigilia son sólo "internas"; el Nivel 1 de mi vida de vigilia no se ve jamás comprometido y es para mi tan absoluto como lo es el sueño para el soñante. Lo que acabo de decir es cercano al tipo de respuesta que da Wittgenstein al escepticismo basado en el argumento del sueño; véase Sobre la certeza, $\S \S 105-115$ y $\$ 243$ y ss.

18 Como en una historia de un señor al que le pasan ciertas cosas, que lee un libro sobre un señor al que le pasan las mismas cosas, una de las cuales es leer un libro sobre un señor, etcétera. Poner dos espejos enfrentados da una mejor idea de esto. En narratología se le ha llamado a esta clase de estructura con la expresión francesa que puse entre paréntesis. Yo propondría llamarle a esta posibilidad sueños fractales. En el caso que aquí se menciona es un fractal de apenas dos niveles, pero teóricamente podría tener infinitos.

19 Lo que sigue es un ensayo, con toda la falibilidad que de suyo entraña el ensayar. En casos como éstos es difícil que cada paso de la descripción guarde el apego a la intuición deseable en fenomenología. Todo lo que puede hacerse es Ilenar las lagunas intuitivas con la mayor consistencia posible.

20 Heidegger describe esta especial indeterminación con que se capta el regreso a la vigilia, de la siguiente manera: "El momento del reconocer, incluso no como un acto explícito del reconocer, sino del simple volver, eso pertenece al despertar", op. cit., p. 308. Conviene señalar, de paso, que, aun en un despertar abrupto, tiene que haber una fase de este tipo; es sólo que se la atraviesa tan velozmente que el tránsito por ella pasa completamente inadvertido.

21 Aunque estrictamente no debería decirse el límite, sino que habria que hablar de uno de sus límites, pues no sabemos si, así como la "vida onírica" limita con la vida de vigilia, no limi- 
tará también con la muerte misma (o si la muerte misma no será aquel otro Nivel 2, del que al fin alcanzaríamos a tener noticia, y en donde se nos mostraría ique nuestra vida ha sido un sueño!).

22 Las descripciones que nos han llevado a afirmar esto echan por tierra, a mi parecer, los cuestionamientos de Malcolm y Dennett acerca de si los sueños son o no experiencias.

23 Esto debería ser desarrollado mucho más. ¿Cómo es que lo recién percibido llega a mostrarse a la conciencia de vigilia como algo recién soñado? ¿Sobre qué fundamentos descansa la posibilidad de esta marca y de la distinción que le subyace entre el soñar y la vigilia? He dado algunas pocas indicaciones, como la de una conciencia de regreso a lo mismo, ausente en FR. Más adelante diré todavía algo más.

24 Lo escribo entre comillas porque estoy haciendo un uso muy amplio del concepto de olvido.

25 A diferencia de lo que sucedía con uno de los casos del tipo "Esto es un sueño", en donde sólo se llegaba a captar negativamente la vigilia, como un ámbito de no-sueño, sin alcanzar a aprehenderla.

26 Como si, por utilizar una analogía, uno estuviera conduciendo un automóvil, con vistas a llegar a cierto lugar (la meta), y toda su atención estuviera dirigida a la carretera. En algún momento, puede percibirse con el rabillo del ojo que al costado queda atrás un cartel, pero no qué era lo que decía el cartel. ( 0 quizá sea que más bien uno mira brevemente hacia el costado y ve un cartel, pero de modo demasiado fugaz como para aprehender qué es lo que éste exhibe.)

27 No puedo aquí ocuparme de exponer una fenomenología de las aso- ciaciones, en la quedaría de manifiesto cómo es que ciertos sentidos que comparecen en el presente vivo despiertan, por obra de una asociación, sentidos que se encuentran hundidos en un "fondo retencional indiferenciado". Así, pues, si nada, en la conciencia de quien recién despierta, convoca, a través de un nexo asociativo, el sueño ya hundido, éste no será recordable. Remito al lector a los Análisis sobre sintesis pasiva de Husserl, § 27 y §§ 36-38; también a mi Autobiografía y presente vivo. Un estudio fenomenológico, cap. segundo, III.2.

28 Es difícil decir si esta situación se da efectivamente o no. En las últimas líneas de su tratado sobre lo sueños Aristóteles testimonia que "hay casos de personas que, en toda su vida, nunca han tenido un sueño" (esto no nos exime de considerar que esas personas bien pudieron ser incapaces de recordar un solo sueño en todas sus vidas). Como sea, lo que importa aquí es determinar a priori las diversas posibilidades, más allá de si se realizan o no empíricamente.

29 Experiencia y juicio, § 39, p. 184, cursivas de Husserl. Véanse también los §§ 39-41.

30 Para dar cuenta de este olvido no ha sido preciso apelar a conceptos tales como represión o censura, conceptos que se fundan, necesariamente, en un juego de transacciones del que es imposible tener evidencia fenomenológica, como en la psicodinámica freudiana que está a la base de su teoría de los sueños. Véase S. Freud, La interpretación de los sueños, en particular el cap. 10, titulado "Psicología de los procesos oníricos"; la primera sección de este capítulo está dedicada al olvido de los sueños.
31 Y se presta a diversos fines, desde un estudio de caso, hasta una reflexión eidética.

32 En relación a este punto, sólo se ha señalado un aspecto. Una respuesta cabal reclamaría un examen de la relación entre los sueños (no ya el soñar) y la vigilia, o más bien, de la vigilia y los sueños. Las páginas que siguen apuntan hacia allí.

33 Prefiero hablar de regularidad más bien que de necesidad o legalidad (si bien antes me vali de este término y lo haré cuando parezca indispensable). Intento con esto, además de evitar una serie de problemas que los otros términos traerían consigo, remitirme a la experiencia "de término medio", por utilizar una expresión heideggeriana.

34 ¿Y el ámbito lógico? ¿Puedo soñar con un círculo cuadrado? Seguramente no, pues lo que es lógicamente imposible, puesto que no es siquiera pensable, no puede ser soñable. Podría uno soñar con un círculo y tener la certeza de que es un círculo cuadrado, "saberlo" círculo cuadrado mientras lo sueña, pero esto sólo indica la latitud del "saber" algo en sueños.

35 Husserl le llama así en sus Análisis sobre sintesis pasiva. La descripción de esta sintesis es básicamente la misma que ya se había ofrecido en las Lecciones de fenomenología de la conciencia interna del tiempo, dictadas entre 1905 y 1910 . Husserl partía entonces de la pregunta de cómo es que un objeto se aparece a la conciencia como duradero y se veía llevado a describir un presente "espacioso", en el que coexisten las intenciones temporales de lo que todavía-no-es (protención: la conciencia de lo inminentísimo), de lo que es ahora (impresión) y de lo recién- 
sido (retención). Las lecciones no se agotan en esto, sino que van mucho más allá; aquí sólo doy un apretadísimo resumen. En los Análisis sobre sintesis pasiva se enfatiza el carácter fundante de la síntesis trascendental del tiempo, vista como "un marco de trabajo universal, formal", "una forma sintéticamente constituida en la que toda otra posible sintesis debe participar", ACPAS, § 27, pp. 170-171 [Hua XI, p. 125], la traducción es mía. En esta sintesis se constituye, no sólo la forma del flujo y la condición necesaria - pero no suficiente- de unidad e identidad de un objeto (mediante la retención del sentido objetivo dado a la conciencia en la impresión), sino que se constituyen también las relaciones de coexistencia y sucesión entre los objetos inmanentes.

36 Julia Iribarne aventura, en una dirección distinta, una tesis sugerente para explicar por qué creemos todo aquello que los sueños presentan. Dice en su conferencia: "cuando la actividad de la sintesis pasiva no está orientada a la organización perceptiva y a su capacidad crítica en su procedimiento de posición, eventual desengaño y corrección de lo puesto como percepto, sin esas operaciones en funcionamiento, el centro yoico de la sintesis pasiva cree. La neutralización de la posición, esto es la duda, la interrogación, son propias de la conciencia perceptiva en el proceso de plenificación o implesión del percepto".

37 Aunque también, si bien no puedo aqui desarrollar esto como debería, la continuidad tiene que tener que ver con sintesis pasivas de asociación entre contenidos sucesivos.

38 Apenas ahora advierto esto, y veo que se suma a lo dicho antes para apoyar la autonomía del soñar (lo dicho antes es que los sueños que se recuerdan son sólo el caso límite en el espacio lógico de los sueños posibles).

39 La clasificación de Artemidoro es un poco más complicada y distingue, en primer lugar, los sueños proféticos o premonitorios (óneiroi) de aquellos que no lo son (enýpnia); los primeros son divididos entre sueños directos, que muestran el cumplimiento inminente de ciertos eventos, representándolos con fidelidad, y sueños simbólicos, que muestran eventos de un futuro lo suficientemente separado del momento del presagio como para que sea requerida una interpretación. Véase Artemidoro, La interpretación de los sueños, caps. I y IV.

40 Estos factores son: condensación, desplazamiento, adaptación a los medios de representación propios del soñar y un cuarto que no siempre tiene lugar, según Freud, y al que él llama el cuidado de la representación (da un aspecto más coherente al sentido manifiesto, pero a la vez oculta más el sentido latente). Véase, S. Freud, op. cit., caps. 1 (vol. 1) y 7 (vol. 2).

41 Hay algo así como una "proyección" de la teleología de la razón en los sueños mismos, por ponerlo en términos freudianos. Pero Freud dice a la vez esto: "La concepción precientífica de los antiguos sobre los sueños se hallaba seguramente de completo acuerdo con su total concepción del Universo, en la que acostumbraban proyectar como realidad en el mundo exterior aquello que sólo dentro de la vida anímica la poseía" (!), ibid., vol. 1, p. 70, la cursiva es mía.

42 "Me parece que el pozo es símbolo de la ciencia, pues su naturaleza no es superficial, sino muy profunda. No se expone públicamente, sino que suele esconderse de algún modo y hacerse invisible y no se encuentra fácilmente sino a duras penas con muchos esfuerzos"; Filón de Alejandría, Sobre los sueños, Libro I, p. 53. En este pasaje, Filón hace un preámbulo a la interpretación del sueño de la escalera, soñado por Jacob; no es todavía la interpretación del sueño, pero el preámbulo se vale de la misma hermenéutica simbólica.

43 Además del lema fenomenológico al que aquí hago alusión, seria injusto dejar de mencionar un artículo que tiene una impronta muy semejante en su ataque contra la interpretación, si bien en el ámbito artístico; es el conocido ensayo de Susan Sontag, de 1964, titulado "Contra la interpretación". Dice la autora: "El intérprete, sin llegar a suprimir o reescribir el texto, lo altera. Pero no puede admitir que es eso lo que hace. Pretende no hacer otra cosa que tornarlo inteligible, descubriéndonos su verdadero significado", p. 29. "Al reducir la obra de arte a su contenido para luego interpretar aquello, domesticamos la obra de arte. La interpretación hace manejable y maleable el arte", p. 31. "La interpretación, basada en la teoría, sumamente cuestionable, de que la obra de arte está compuesta por trozos de contenido, viola el arte. Convierte el arte en artículo de uso, en adecuación a un esquema mental de categorias", p. 34. Por último: "Quienes buscan una interpretación freudiana del tanque [se refiere a una escena de El silencio, de Bergman] sólo expresan su falta de respuesta a lo que transcurre en la pantalla", p. 33; la cursiva es de Sontag. 


\section{BIBLIOGRAFÍA}

Aristóteles: On dreams, tr. J. I. Beare, en The Complete Works of Aristotle, ed. Jonathan Barnes, vol. 1, pp. 729-735.

Artemidoro (1989): La interpretación de los sueños, intro., tr. y notas Elisa Ruiz Garcia, Gredos, Madrid.

Dennett, D. (1972): "Are Dreams Experiences?", The Philosophical Review, vol. 85, n. 2 2, Apr., pp. 151-171 (versión castellana: "¿Son experiencias los sueños?", tr. Rosario Amieva, Cuadernos de Crítica, 33, Instituto de Investigaciones Filosóficas-UNAM, México D.F., 1981).

Descartes, R. (2002): Discurso del método y Meditaciones metafísicas, tr. Manuel García Morente, Tecnos, Madrid.

Filón de Alejandría (1997): Sobre los sueños - Sobre José, intr., tr. y notas Sofía Torallas Tovar, Gredos, Madrid.
Freud, S. (2006): La interpretación de los sueños (3 vols.), tr. Luis López-Ballesteros y de Torres, Alianza, Madrid.

Heidegger, M. (2007): Seminarios de Zollikon, ed. Medard Boss, tr. Ángel Xolocotzi Yáñez, Jitanjáfora, Morelia.

Husserl, E. (2001): Analyses Concerning Passive and Active Synthesis, intro. y tr. Anthony J. Steinbock, Kluwer, Dordrecht/Boston/London.

- (1980): Experiencia y juicio, tr. Jas Reuter, UNAM, México D.F.

- (2002): Lecciones de fenomenología de la conciencia interna del tiempo, intro., tr. y notas Agustín Serrano de Haro, Trotta, Madrid.

- (2005): Phantasy, Image Consciousness, and Memory (1898-1925), tr. John B. Brough, Springer, Dordrecht.

Iribarne, J. (2001): "Aportaciones para una fenomenología de los sueños", conferencia de clausura del XII Encuentro de Fenomenología y Hermenéutica, Centro de Estudios Filosóficos-Academia Nacional de Ciencias de Buenos Aires, leida el 21 de septiembre.

Malcolm, N. (1956): "Dreaming and Skepticism", The Philosophical Review, vol. 65, n. 1 , Jan., pp. 14-37.

Platón (2006): Teeteto, intro., trad. y notas Marcelo Boeri, Losada, Bs. As.

Schutz, A. y Luckmann, T. (2001): Las estructuras del mundo de la vida, Amorrortu, Bs. As.

Schutz, G. (2007): Autobiografía y presente vivo. Un estudio fenomenológico, tesis de maestría, UNAM, México D.F., marzo.

Sontag, S. (1998): "Contra la interpretación", en Contra la interpretación, tr. Horacio Vázquez Rial, Alfaguara, Madrid, 1998, pp. 25-39.

Wittgenstein, L. (1988): Sobre la certeza, trs. J. L. Prades y V. Raga, Gedisa, Barcelona. 